\title{
Phenolic compounds and biopotential of grape pomace extracts from Prokupac red grape variety
}

\author{
Danijel D. Milinčića ${ }^{\mathrm{a}}$, Nemanja S. Stanisavljević ${ }^{\mathrm{b}}$, Aleksandar Ž. Kostića ${ }^{\mathrm{a}}$, \\ Svetlana Soković Bajić ${ }^{\mathrm{b}}$, Milan O. Kojić ${ }^{\mathrm{b}}$, Uroš M. Gašićc ${ }^{\mathrm{c}}$, Miroljub B. Barać ${ }^{\mathrm{a}}$, \\ Sladjana P. Stanojevićc ${ }^{a}$, Živoslav Lj Tešić ${ }^{\mathrm{d}}$, Mirjana B. Pešić ${ }^{\mathrm{a},{ }^{*}}$ \\ ${ }^{a}$ University of Belgrade, Faculty of Agriculture, Department of Food Technology and Biochemistry, Nemanjina 6, 11081, Belgrade, Serbia \\ ${ }^{\mathrm{b}}$ University of Belgrade, Institute of Molecular Genetics and Genetic Engineering, P.O. Box 23, 11 010, Belgrade, Serbia \\ ' University of Belgrade, Institute for Biological Research "Siniša Stanković", National Institute of Republic of Serbia, Department of Plant Physiology, Bulevar despota \\ Stefana 142, 11060, Belgrade, Serbia \\ ${ }^{\mathrm{d}}$ University of Belgrade, Faculty of Chemistry, P.O. Box 51, 11158, Belgrade, Serbia
}

\section{A R T I C L E I N F O}

\section{Keywords:}

Wine by-products

Phenolic compounds

Antioxidant activity

Cytotoxic activity

Cellular antioxidant activity

\begin{abstract}
A B S T R A C T
Phenolic compounds and biopotential (antioxidant, cellular antioxidant and cytotoxic activity) of grape pomace (GP) skin, seed, stem and whole GP originating from indigenous red grape variety Prokupac were evaluated. The UHPLC-Orbitrap $\mathrm{MS}^{4}$ analysis showed the presence of 75 phenolic compounds (57 non-anthocyanins and 18 anthocyanins), among which considerable content of ethyl gallate was observed and malvidin-3-O-hexoside$(8,8)$-methylmethyne-(epi)catechin was identified. The stem had significant content of stilbenoids. The GP seed and the whole GP showed the highest antioxidant activity estimated by ABTS• ${ }^{+}$DPPH• and $\mathrm{H}_{2} \mathrm{O}_{2}$ scavenging assays that were strongly correlated with the presence of flavan-3-ols, phenolic acids and ethyl gallate. The GP skin exerted cellular antioxidant activity on adenocarcinoma cells $\left(\mathrm{EC}_{50}=56.4 \mathrm{mg} \mathrm{TPCs} / \mathrm{mL}\right)$ which was strongly correlated with the presence of flavonols and anthocyanins. These by-products of Prokupac red grape variety are a notable source of phenolic compounds with good antioxidant activity that can be extensively used in food and pharmaceutical industry.
\end{abstract}

\section{Introduction}

After the traditional process of wine production from fermented grapes, a significant amount (approximately $10-30 \%$ of total grape weight) of by-products, such as pomace, skin, stem and seed are obtained (Muhlack, Potumarthi, \& Jeffery, 2018). The total quantity of grape pomace generated worldwide is millions of tonnes per year which raises a waste management issue from both ecological and economica (Muhlack et al., 2018). Apart from the traditional use of grape pomace as composting material and animal feed, numerous studies indicate new opportunities for utilization of extracted GP components such as phenolic compounds (PCs) in value-added products (Fontana, Antoniolli, \& Bottini, 2013; Muhlack et al., 2018).

Most researches are focused on quantification and determination of PCs extracted from grape pomace or its constituents of regionally important cultivars such as those from Argentina (Antoniolli, Fontana,
Piccoli, \& Bottini, 2015), Germany (Kammerer, Claus, Carle, \& Schieber, 2004), USA (Deng, Penner, \& Zhao, 2011), Brazil (Ribeiro et al., 2015; Rockenbach et al., 2012), Portugal (Oliveira, Alhinho da Silva, Teixeira, De Freitas, \& Salas, 2015; Peixoto et al., 2018), Greece (Anastasiadi, Pratsinis, Kletsas, Skaltsounis, \& Haroutounian, 2012; Drosou, Kyriakopoulou, Bimpilas, Tsimogiannis, \& Krokida, 2015), France (Ky, Lorrain, Kolbas, Crozier, \& Teissedre, 2014) and Serbia (Pintać et al., 2018). These studies on regionally important cultivars showed that the anthocyanins such as 3-O-glycosides of malvidin, petunidin, cyanidin, peonidin and delphinidin are dominant phenolic compounds found in the GP skin, the flavan-3-ols known as catechins and proanthocyanidins are present in the GP seed, while proanthocyanidins and stilbens are found to be dominant in the GP stem. Despite the fact that the PCs of GP extracts of numerous grape varieties had already been characterised, many autochthonous varieties have not yet been evaluated such as indigenous red grape variety Prokupac originating from Župa, a famous

\footnotetext{
* Corresponding author.

E-mail address: mpesic@agrif.bg.ac.rs (M.B. Pešić).
} 
winery region in central Serbia. Prokupac is one of the most known autochthonous varieties grown in this region (Zdunić et al., 2019). It was already reported that the grape seed flour of Prokupac variety has unique fatty acids and soluble sugar profiles (Milinčić et al., 2020) and the highest total phenolic content (TPC) compared to the seeds of other red grape (Cabernet Sauvignon, Merlot, Cabernet Franc, Sangiovese and Shiraz) and white grape (Riesling, Chardonnay, Sauvignon Blanc, Welschriesling, Pinot Gris, and Petra) varieties (Pantelić et al., 2016). The PCs profiles of whole grape, grape seed, skin and pulp of Prokupac variety have also been reported (Mitić, Souquet, Obradović, \& Mitić, 2012; Pantelić et al., 2016; Pešić et al., 2019; Zdunić et al., 2019), but a detailed analysis of the grape pomace PCs either by spectrophotometric methods or by UHPLC-LTQ OrbiTrap MS technique is still lacking.

Phenolic compounds are known to contribute to antioxidant activity and hence positively affect human health and reduce the risk of developing chronic diseases such as cancer, diabetes, inflammatory and cardiovascular diseases (Yu \& Ahmedna, 2013). Also, PCs from grape pomace and other antioxidant constituents can minimize lipid oxidation or act as an antimicrobial agent against spoilage bacteria in food systems (Fontana et al., 2013; Yu \& Ahmedna, 2013). The majority of previously published studies explored the antioxidant potential of GP extracts by means of various in vitro antioxidant activity assays while the information on the cellular antioxidant and cytotoxic activities was scarce (Peixoto et al., 2018).

Bearing in mind that phenolic compounds can exhibit pro-oxidant activity under certain conditions leading to the formation of reactive oxygen species, which can damage DNA, lipids and other biomolecules (Halliwell, 2008), further studies on the profile of PCs and bioactivity of GP extracts are greatly needed. Knowing that these characteristics are influenced by many factors and could vary among the same variety cultivated in different countries, along with the fact that the biopotential and possible use of autochthonous red grape variety Prokupac is still undefined, the aim of this study was to evaluate PCs profile and bioactive properties (antioxidant, cellular antioxidant and cytotoxic activities) of grape pomace (skin, seed, stem and whole GP) originating from indigenous red grape variety Prokupac. The data obtained in this research could be of great importance for further promotion of grape pomace and its constituents as a cost-effective raw material for food, pharmaceutical and cosmetic industries.

\section{Materials and methods}

\subsection{Chemicals}

Acetonitrile, formic acid and methanol (MS grade) were purchased from Merck (Darmstadt, Germany). All other chemicals were purchased from Sigma Aldrich (St Louis, MO, USA). Standards of PCs were purchased from Fluka AG (Buch, Switzerland).

\subsection{Grape pomace samples}

By-product such as fermented grape pomace of the indigenous red grape variety Prokupac was obtained from winery (Vine House Milinčić) located in the famous wine region of Župa, central Serbia. Grape pomace fractions such as skin, seed and stem were manually separated. Whole $\mathrm{GP}$ and its separate fractions were lyophilized and stored at $-20^{\circ} \mathrm{C}$ prior to analysis.

\subsection{Preparation of phenolic compounds extracts of grape pomace and its constituents}

Aqueous extracts of whole grape pomace and its constituents were prepared according to Pešić et al. (2019). Approximately $1 \mathrm{~g}$ of lyophilized GP stem, seed, skin, or whole GP was extracted with $20 \mathrm{~mL}$ of $80 \%$ aqueous methanol and $0.1 \% \mathrm{HCl}$ for $1 \mathrm{~h}$ with shaking at room temperature. After filtration, the extraction procedure was repeated two times.
Collected filtrates were evaporated to dryness under reduced pressure at $40{ }^{\circ} \mathrm{C}$ and resuspended in $15 \mathrm{~mL}$ of milliQ water. The suspensions were filtrated through $0.45 \mu \mathrm{m}$ syringe filters before further spectrophotometric and UHPLC-Orbitrap $\mathrm{MS}^{4}$ analysis. For determination of cytotoxic properties, the suspensions were filtrated through $0.22 \mu \mathrm{m}$ syringe filters. These extracts represented aqueous grape pomace (AGP) extracts.

\subsection{Phenolic compounds characterization of grape pomace and their constituents}

\subsubsection{Total phenolic, total flavonoid, total proanthocyanidin and monomeric anthocyanin content determination}

Total phenolic content, total flavonoid content (TFC) and total proanthocyanidin content (PAC) in the samples were determined according to the procedures already described by Pešić et al. (2019). Briefly, TPC was determined using a Folin-Ciocalteu's reagent by mixing $70 \mu \mathrm{L}$ of AGP extract, $300 \mu \mathrm{L}$ of Folin-Ciocalteu reagent and $230 \mu \mathrm{L}$ of $7.5 \mathrm{~g} / 100 \mathrm{~mL} \mathrm{Na}_{2} \mathrm{CO}_{3}$. After $1 \mathrm{~h} 30 \mathrm{~min}$ left at room temperature, the absorbance was measured at $765 \mathrm{~nm}$ and the results were expressed as milligrams of gallic acid equivalents per gram of dry weight of grape pomace sample (mg GAE/g DM). TFC was measured by the colorimetric assay based on the formation of a flavonoid-aluminium complex. In the test tube, $125 \mu \mathrm{L}$ of AGP extract, $625 \mu \mathrm{L}$ of milliQ water and $37.5 \mu \mathrm{L}$ of 5 $\mathrm{g} / 100 \mathrm{~mL} \mathrm{NaNO}{ }_{2}$ were mixed. After $6 \mathrm{~min}, 75 \mu \mathrm{L}$ of $10 \mathrm{~g} / 100 \mathrm{~mL} \mathrm{AlCl}$ was added and $250 \mu \mathrm{L}$ of $1 \mathrm{~mol} / \mathrm{L} \mathrm{NaOH}$ was added in the mixture after 5 min' rest at room temperature. The absorbance was measured at 510 $\mathrm{nm}$ and the results were expressed as milligram catechin equivalents per gram of dry weight of grape pomace sample (mg CE/g DM). PAC were determined using the butanol- $\mathrm{HCl}$ assay. In the test tube, $0.5 \mathrm{~mL}$ of AGP sample, $3 \mathrm{~mL}$ of buthanol-HCl (95:5) and $0.1 \mathrm{~mL}$ of iron reagent $(2$ $\mathrm{g} / 100 \mathrm{~mL} \mathrm{FeNH}_{4}\left(\mathrm{SO}_{4}\right)_{2}$ in $\left.2 \mathrm{~mol} / \mathrm{L} \mathrm{HCl}\right)$ were mixed. After incubation of the mixture at $95^{\circ} \mathrm{C}$ for $40 \mathrm{~min}$, the absorbance was measured at $510 \mathrm{~nm}$ and the results were expressed as milligram of proanthocyanidins per gram of dry weight of grape pomace sample (mg PA/g DM) and calculated according to the following equations:

$P A C\left(\frac{m g}{L}\right)=((A s-A c) \times 0.1736 \times D F)$

$\operatorname{PAC}\left(\frac{m g}{g}\right)=\frac{\left[\frac{P A C\left(\frac{m g}{L}\right)}{1000}\right]}{m}$

where Ac represents the absorbance of blank, As is the absorbance of samples, DF is the dilution factor and 0.1736 is the conversion factor.

Monomeric anthocyanin content (MAC) was evaluated using the $\mathrm{pH}$ differential method (Rockenbach et al., 2012). Samples were adequately diluted and dissolved in the potassium chloride $(0.025 \mathrm{~mol} / \mathrm{L}, \mathrm{pH} 1.0)$ and sodium acetate $(0.4 \mathrm{~mol} / \mathrm{L}, \mathrm{pH} 4.5)$ buffers. Absorbance was measured at two different wavelengths, $520 \mathrm{~nm}$ and $700 \mathrm{~nm}$ for each sample. Content of the total monomeric anthocyanins was expressed as milligrams of malvidin-3-O-glucoside equivalents per $100 \mathrm{~g}$ of dry weight of grape pomace sample (mg M3G/100 g DM) and calculated according to the following equations:

$$
\begin{aligned}
& A=(A 520-A 700) p H 1.0-(A 520-A 700) p H 4.5 \\
& M A C\left(\frac{m g}{L}\right)=(A \times M W \times D F \times 1000) /(\varepsilon \times l)
\end{aligned}
$$

$\operatorname{MAC}\left(\frac{m g}{100 g}\right)=\frac{\left[\frac{\operatorname{MAC}\left(\frac{m g}{L}\right)}{1000}\right]}{m} \times 100$

where $A$ represents absorbance, $D F$ is a dilution factor, $M W$ is the 
molecular weight of the malvidin-3-O-glucoside (493.5), $\varepsilon$ is the molar absorptivity of the malvidin-3-O-glucoside (28000).

\subsubsection{UHPLC-orbitrap $M S^{4}$ qualitative analysis}

Separations of PCs were performed using an Accela ultra highperformance liquid chromatography (UHPLC) system coupled to a linear ion trap - orbitrap mass spectrometer (LTQ OrbiTrap MS) equipped with a heated electrospray ionisation probe (HESI-II, ThermoFisher Scientific, Bremen, Germany) in negative ionisation mode for nonanthocyanins and positive ionisation mode for anthocyanins. A Syncronis C18 column $(100 \times 2.1 \mathrm{~mm}, 1.7 \mu \mathrm{m})($ ThermoFisher Scientific, Bremen, Germany) at $40{ }^{\circ} \mathrm{C}$ was used for compound separation. Chromatographic and MS parameters were previously described by Pešić et al. (2019). Xcalibur software (version 2.1) was used for the instrument control, data acquisition and data analysis.

The detected PCs were quantified using commercially available standards and expressed as milligrams per kilogram of dry weight (mg/ $\mathrm{kg}$ DM). All PCs standards (gallic acid, protocatechuic acid, $p$-hydroxybenzoic acid, gentisic acid, vanillic acid, caffeic acid, chlorogenic acid, p-coumaric acid, ferulic acid, catechin, quercetin 3-O-rutinoside, quercetin 3-O-glucoside, quercetin 3-O-rhamnoside, kaempferol 3-O-glucoside, isorhamnetin 3-O-glucoside, quercetin, kaempferol, isorhamnetin, resveratrol, resveratrol 3-O-glucoside, delphinidin 3-O-glucoside, malvidin 3,5-di-O-glucoside, cyanidin 3-O-glucoside, cyanidin 3-O-sambubioside, cyanidin 3-O-arabinoside, pelargonidin 3-O-glucoside, peonidin 3-O-glucoside, and malvidin 3-O-glucoside) were of analytical grade (from $95 \%$ to $99 \%$ purity) (Fluka AG, Buchs, Switzerland). For those phenolic compounds for which the corresponding standards had not been available, the identification was done based on their exact molecular masses and specific MS fragmentation and confirmed by literature data (Oliveira et al., 2015; Pantelić et al., 2016; Peixoto et al., 2018; Pešić et al., 2019; Zhang et al., 2020). The content of those PCs was expressed as the milligram of dominant compound in the respective class of PCs per kilogram of dry weight. Accurate masses of components were calculated by using ChemDraw software (version 12.0, CambridgeSoft, Cambridge, MA, USA)

Table S1 shows a list of quantified phenolic compounds together with their equation parameters, limits of detection (LOD), limits of quantification (LOQ), correlation coefficient $\left(\mathrm{r}^{2}\right)$ and linearity ranges.

\subsection{Antioxidant properties}

\subsubsection{Ferric reducing power assay (FRP) and ABTS cation radical scavenging activity (ABTS) assay}

Ferric reducing power and the free radical scavenging activity of prepared AGP extracts were evaluated according to the procedures previously described by Pešić et al. (2019). Briefly, $250 \mu \mathrm{L}$ of AGP extracts, $250 \mu \mathrm{L}$ of $0.2 \mathrm{~mol} / \mathrm{L}$ phosphate buffer $\mathrm{pH} 6.6$ and $250 \mu \mathrm{L}$ of 1 $\mathrm{g} / 100 \mathrm{~mL}$ potassium ferricyanide solution were mixed. After incubation of the mixture for $20 \mathrm{~min}$ at $50{ }^{\circ} \mathrm{C}, 250 \mu \mathrm{L}$ of $10 \mathrm{~g} / 100 \mathrm{~mL}$ TCA was added and the mixture was centrifuged at $17000 \mathrm{~g}$ for $5 \mathrm{~min}$. Then, 500 $\mu \mathrm{L}$ of supernatant, $500 \mu \mathrm{L}$ of milliQ water and $100 \mu \mathrm{L}$ of $0.1 \mathrm{~g} / 100 \mathrm{~mL}$ ferric chloride were mixed and after $10 \mathrm{~min}$, absorbance at $700 \mathrm{~nm}$ was measured. FRP was expressed as absorbance of the reaction mixtures at $700 \mathrm{~nm}$.

For determination of ABTS cation radical scavenging activity the stock solution of ABTS ${ }^{+}(7 \mathrm{mmol} / \mathrm{L}$ aqueous solution of ABTS $(2,2-$ azino-bis/3-ethil-benothiazoline-6-sulphonic acid) with $2.45 \mathrm{mmol} / \mathrm{L}$ potassium persulfate)) was prepared $16 \mathrm{~h}$ before analysis. Priory to analysis, $\mathrm{ABTS} \bullet{ }^{+}$working solution was prepared by diluting the stock solution with methanol to obtain an absorbance between 0.7 and 0.8 at $734 \mathrm{~nm}$. In the test tube, $10 \mu \mathrm{L}$ of AGP extracts and $1 \mathrm{~mL}$ of ABTS $\bullet^{+}$ working solution were mixed and after $7 \mathrm{~min}$ the absorbance of the mixture was measured at $734 \mathrm{~nm}$. The results were expressed as micrograms of ascorbic acid equivalents per millilitre of grape pomace sample ( $\mu \mathrm{gAAE} / \mathrm{mL})$.
2.5.2. Measurement of relative DPPH radical scavenging capacity (DPPH RDSC)

Relative DPPH radical scavenging capacity measurement was determined according to Cheng, Moore, and Yu (2006). Reaction mixture $(100 \mu \mathrm{L})$ consisted of supernatant diluted with methanol. Five different volumes (10, 20, 40, 60 and $80 \mu \mathrm{L}$ ) of AGP extracts and Trolox were used. Then, $100 \mu \mathrm{L}$ of $200 \mu \mathrm{mol} / \mathrm{L}$ DPPH radical in methanol was added to each well of microtiter plate and shaken. Blank contained 200 $\mu \mathrm{L}$ of methanol, while control sample was prepared by mixing $100 \mu \mathrm{L}$ of methanol and $100 \mu \mathrm{L}$ of DPPH radical solution. Absorbance was continuously recorded each minute for $1.5 \mathrm{~h}$ at $515 \mathrm{~nm}$. The percent of DPPH radical quenched for each time point was calculated according to equation (6):

$\%$ DPPH radical quenched $=\left[1-\left(\mathrm{A}_{\text {sample }}-\mathrm{A}_{\text {blank }}\right) /\left(\mathrm{A}_{\text {control }} \mathrm{A}_{\text {blank }}\right)\right] \times 100(6)$

The values of DPPH radical in percentage quenched in different time points for each extract and standard were plotted against reaction time. Area under the curve (AUC) was determined according to the following equation:

$\mathrm{AUC}=0.5 f_{0}+\left(f_{1}+f_{2}+f_{3}+\ldots .+f_{\mathrm{i}-1}\right)+0.5 f_{\mathrm{i}}$

where $f_{0}$ represents DPPH radical quenched at the start of the measurement and $f_{\mathrm{i}}$ is DPPH radical quenched at reaction time $i$. Relative DPPH radical scavenging capacity was calculated according to equation (8):

$\mathrm{DPPH}$ RDSC $=\mathrm{AUC}_{\mathrm{sample}} / \mathrm{AUC}_{\text {trolox }} \times$ molarity trolox $/$ volume sample

and expressed as millimole of Trolox equivalents per gram of dry weight of grape pomace sample (mmol TE/g DM).

\subsubsection{Hydrogen peroxide scavenging assay (HPS)}

Scavenging of $\mathrm{H}_{2} \mathrm{O}_{2}$ was determined according to the method of $\mathrm{Hu}$, Chen, $\mathrm{Xu}$, and $\mathrm{Lu}$ (1992). In this method luminol- $\mathrm{H}_{2} \mathrm{O}_{2}$ system was applied to measure the scavenging effect of AGP extracts. The luminescent reaction was initiated by mixing diluted AGP extracts with $1 \mathrm{~mL}$ of solution containing $100 \mathrm{mmol} / \mathrm{L}$ luminol, dissolved in $50 \mathrm{mmol} / \mathrm{L}$ carbonate buffer, $\mathrm{pH}$ 9.4. Light emission was recorded immediately upon mixing the compounds and it lasted for $200 \mathrm{~s}$ with $15 \mathrm{~s}$ kinetic interval between measurements. In the control sample solutions were replaced with carbonate buffer and background luminescence was recorded without hydrogen peroxide. The area under the obtained curves (for different total phenolic compounds (TPCs) concentrations, $\mu \mathrm{g}$ TPCs/mL of AGP extracts) represents relative luminescent intensity (CL). The scavenging activity was calculated using the following equation:

HPS activity $\left.(\%)=\left[\left(\left(\mathrm{CL}_{\mathrm{c}}-\mathrm{CL}_{0}\right)-\left(\mathrm{CL}_{\mathrm{s}}-\mathrm{CL}_{0}\right)\right) /\left(\mathrm{CL}_{\mathrm{c}}-\mathrm{CL}_{0}\right)\right)\right] \times 100$

where $\mathrm{CL}_{\mathrm{c}}$ represents relative luminescence of the control, $\mathrm{CL}_{\mathrm{s}}$ is relative luminescence of the samples and $\mathrm{CL}_{0}$ represents background luminescence. The HPS activity was expressed as EC50 value (half maximal effective concentration of TPCs). .

\subsection{Cytotoxic properties}

\subsubsection{MTT assay}

The cytotoxicity of grape extracts on Caco- 2 cell line was estimated through a micro-culture tetrazolium [MTT, 3-(4,5-dimethylthiazol-2yl)-2,5-diphenyltetrazolium bromide] assay (Mosmann, 1983). After 24 $\mathrm{h}$ of post inoculation (40-60\% confluency), different concentrations of TPCs of the grape pomace extracts were added to the eukaryotic cells. All treated cells were then incubated for additional 24 and $48 \mathrm{~h}$. After the treatment, MTT was added at the final concentration of $0.5 \mathrm{mg} / \mathrm{mL}$. The plates were incubated for $4 \mathrm{~h}$ in $5 \% \mathrm{CO}_{2}$ at $37{ }^{\circ} \mathrm{C}$ in the dark. Formazan crystals created in MTT-exposed live cells were dissolved by adding $10 \mathrm{~g} / 100 \mathrm{~mL}$ sodium-dodecyl sulphate (SDS) in $0.01 \% \mathrm{HCl}$. The 
wells were then incubated at $37^{\circ} \mathrm{C}$ overnight. Adsorption of the dissolved formazan crystals was measured using Plate Reader Infinite 200 pro at $570 \mathrm{~nm}$. The absorbance at $570 \mathrm{~nm}$ represents the measure of cells metabolic activity. Metabolic activity was calculated using equation (10):

Metabolic activity $(\%)=(A$ of treated cells $/ A$ of nontreated cells $) \times 100(10)$

where $A$ is absorbance. The results were expressed as fold change in metabolic activity compared to control group of untreated cells.

\subsubsection{Cellular antioxidant activity assay (CAA)}

Cellular antioxidant activity assay was conducted according to the method of Wolfe and Liu (2007) with certain modifications (Kellett, Greenspan, \& Pegg, 2018). Human epithelial colorectal adenocarcinoma cells (Caco-2 cell line, European Collection of Cell Cultures-ECACC No. 86010202) were used in the assay since they are more suitable for measuring the effectiveness of dietary antioxidants (Kellett et al., 2018). The cultivation and maintenance of the cell line was carried out in Dulbecco's Modified Eagle Medium according to (Sánchez, Fernández-García, Margolles, de los Reyes-Gavilán, \& Ruas-Madiedo, 2010). Cells were cultivated in a humidified $5 \% \mathrm{CO}_{2}$ incubator at $37^{\circ} \mathrm{C}$. For the assay Caco-2 cells were grown in 24 well plates until monolayers formed with no further visible differentiation Afterward, the monolayers were dissociated from the surface using $0.05 \%$ trypsin-EDTA (Sigma). Cells were then plated $\left(6 \times 10^{4}\right.$ cells per well) in 96 well, black, flat bottom plates (Corring, VWR, Suwanee, USA) and cultivated until confluency. Cultivation medium was then removed, and the cells were washed with PBS and supplemented with $50 \mu \mathrm{L}$ of $25 \mu \mathrm{mol} / \mathrm{L} 2^{\prime}, 7^{\prime}$-dichlorofluorescin diacetate (DCFH-DA) and $50 \mu \mathrm{L}$ of growth medium containing aqueous grape pomace extracts. Control sample consisted of $50 \mu \mathrm{L}$ DCFH-DA solution and $50 \mu \mathrm{L}$ of medium. Plates were then incubated for $1 \mathrm{~h}$ at $37{ }^{\circ} \mathrm{C}$ in humidified $5 \% \mathrm{CO}_{2}$ incubator. After incubation the cells were quickly washed two times with PBS and the reaction was initiated by adding $100 \mu \mathrm{L}$ of $600 \mu \mathrm{mol} / \mathrm{L} 2,2$ '-azobis (2-amidinopropane) dihydrochloride (ABAP), free radical generator. Kinetic measurement was conducted with emission at $520 \mathrm{~nm}$ and excitation at $485 \mathrm{~nm}$ during $1 \mathrm{~h}$ with $90 \mathrm{~s}$ interval. Collected data were processed by calculating the area under the curve (AUC) for each sample and control sample using the following formula:

$\mathrm{AUC}=\left[\mathrm{F}_{1} / 2+\operatorname{sum}\left(\mathrm{F}_{2}: \mathrm{F}_{\mathrm{n}-1}\right)+\mathrm{F}_{\mathrm{n}} / 2\right] \times \mathrm{CT}$

where $F_{1}$ represents initial fluorescence red in the first measurement, Fn is the fluorescence recorded in the last measurement and CT is kinetic cycle time in minutes. Net AUC values were obtained by subtracting blank AUC values from the AUC values of samples and the control sample. The CAA unit was calculated as follows:

CAA unit $=100-\left(\right.$ net $\mathrm{AUC}_{\text {sample }} /$ net $\left.\mathrm{AUC}_{\text {control }}\right) \times 100$

The concentration of TPCs (mg TPCs/mL of AGP extracts) required to cause a $50 \%$ inhibition of fluorescence i.e. $\mathrm{EC}_{50}$ value, was calculated using software Quest Graph ${ }^{\mathrm{TM}}$ EC50 Calculator.

\subsection{Statistical analysis}

The results are expressed as the mean of three measurements \pm standard deviation (SD). Student's $t$-test and ANOVA analysis with Duncan's post hoc test were used to determine the significant differences between means at $p<0.05$. The Pearson's correlation coefficient $(r)$ was determined to calculate the relationship between different antioxidant tests and phenolic compounds. Statistical analysis was carried out using Statistica software version 8.0 (StatSoft Co., Tulsa, OK, USA).

\section{Results and discussion}

3.1. Total phenolic, total flavonoid, total proantocyanidin and total monomeric anthocyanin content

Results of spectrophotometric determination of PCs are presented in Fig. 1a, b, c and d. Significant differences $(p<0.05)$ were observed among all tested samples for all investigated parameters. The whole AGP extract showed to have the highest content of total PCs $(38.7 \pm 0.36 \mathrm{mg}$ GAE/g DM), followed by AGP seed, stem and skin extracts, respectively (Fig. 1a). The results for TPC were in the range of those reported by other authors for ethanolic, methanolic and aceton extracts of grape pomace and corresponding skin and seed (Ky et al., 2014; Ribeiro et al., 2015; Rockenbach et al., 2012; Tseng \& Zhao, 2012). Moreover, the results for the content of total flavonoids followed the same trend as for the total PCs (Fig. 1b) and ranged from $5.6 \pm 0.16$ to $14.5 \pm 0.24 \mathrm{mg} \mathrm{CE} / \mathrm{g} \mathrm{DM}$ ). These values are lower compared to those reported by Ribeiro et al. (2015) for methanolic extracts of four grape pomace samples (Cabernet Sauvignon, Merlot, Mix and Terci) and Tseng and Zhao (2012) for aceton grape pomace extracts of Merlot and Pinot noir, but similar to data obtained by Pintać et al. (2018) for methanolic and ethanolic grape pomace extracts of Cabernet Sauvignon and Merlot produced in Serbia. High content of total proanthocyanidins was detected in the AGP seed and whole GP extracts, $41.2 \pm 0.62$ and $36.3 \pm 0.24 \mathrm{mg} \mathrm{PA} / \mathrm{g} \mathrm{DM}$, respectively (Fig. 1d). On the other hand, the results for the total monomeric anthocyanins showed their considerable presence in the AGP skin and whole GP extracts $(302.1 \pm 17.24 \mathrm{mg}$ and $221.6 \pm 3.63$ M3G/100g DM), while in the AGP seed and stem extracts they were not detected with the applied method (Fig. 1c). These results are in accordance with the data reported for methanolic grape pomace extracts produced in Brazil (Ribeiro et al., 2015; Rockenbach et al., 2012) and ethanolic grape pomace skin extracts produced in France (Ky et al., 2014), but significantly higher than the data reported for aceton grape pomace and grape pomace skins extracts of Merlot and Pinot noir produced in the USA (Tseng \& Zhao, 2012).

\subsection{UHPLC-orbitrap $M S^{4}$ characterization of phenolic compounds}

The detailed PCs profile of the AGP extracts of whole GP, seed, skin and stem of indigenous Prokupac variety as well as their characterization are presented in Table 1 and Table S2. The identification of PCs using mass spectral analysis by UHPLC-Orbitrap $\mathrm{MS}^{4}$, was done taking into account retention times, molecular masses of the molecular ions $\left([\mathrm{M}-\mathrm{H}]^{-/+}\right)$, individual $\mathrm{MS}^{2}, \mathrm{MS}^{3}$ and $\mathrm{MS}^{4}$ fragment ions and the data from literature. In total, seventy-five phenolic compounds (non-anthocyanins and anthocyanins) were identified and quantified. However, for easier interpretation of the results, they were divided into six distinct classes: 1) hydroxybenzoic acids and derivatives (13 compounds), 2) hydroxycinnamic acids and derivatives (6 compounds), 3) flavan 3-ols and proanthocyanidins (13 compounds), 4) flavonols aglycones and glycosides (16 compounds), 5) stilbenoids (9 compounds) and 6) anthocyanins (18 compounds). Most of the identified PCs are in a bound form and occur either as esters or glycosidic complexes.

Hydroxybenzoic acids and derivatives were detected in significant content in all examined AGP extracts, accounting for $46.34 \%$ (whole pomace), $51.63 \%$ (seed), $14.30 \%$ (skin) and $25.02 \%$ (stem) of total PCs. However, considerable differences were observed in their content among the analysed constituents. Gallic acid hexoside isomer 1 and 2, dominated in the AGP seed extract, while di- and hydroxybenzoic acid hexosides were predominant in the AGP skin and stem extracts. Additionally, substantial content of ethyl gallate was observed in all analysed samples $(22.2 \%, 18.9 \%, 23.05$ and $21.2 \%$ of total hydroxybenzoic acids and derivatives in the AGP seed, skin, stem and whole pomace extracts, respectively) probably due to the alcoholic fermentation to which the grape pomace was subjected before analysis (proposed fragmentation pathway of ethyl gallate is presented in Fig. 2a). It was recently reported 
a

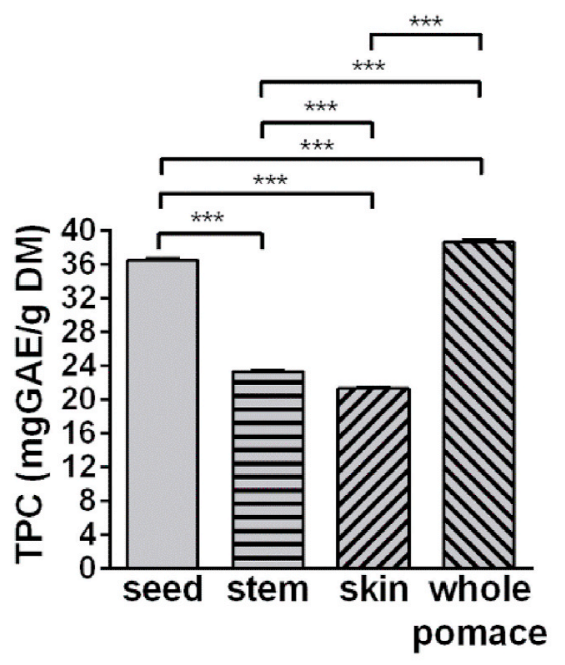

C

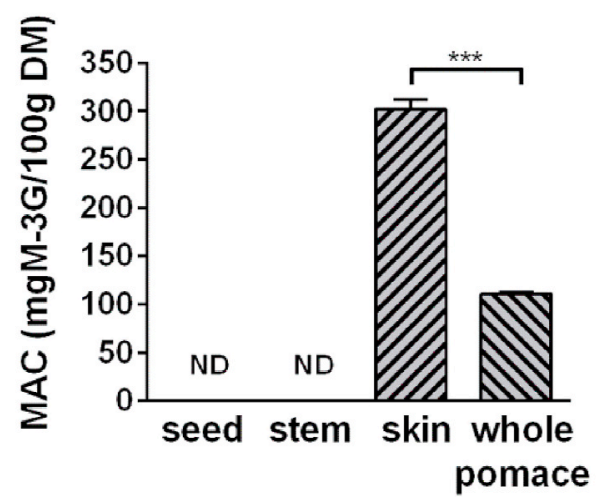

b
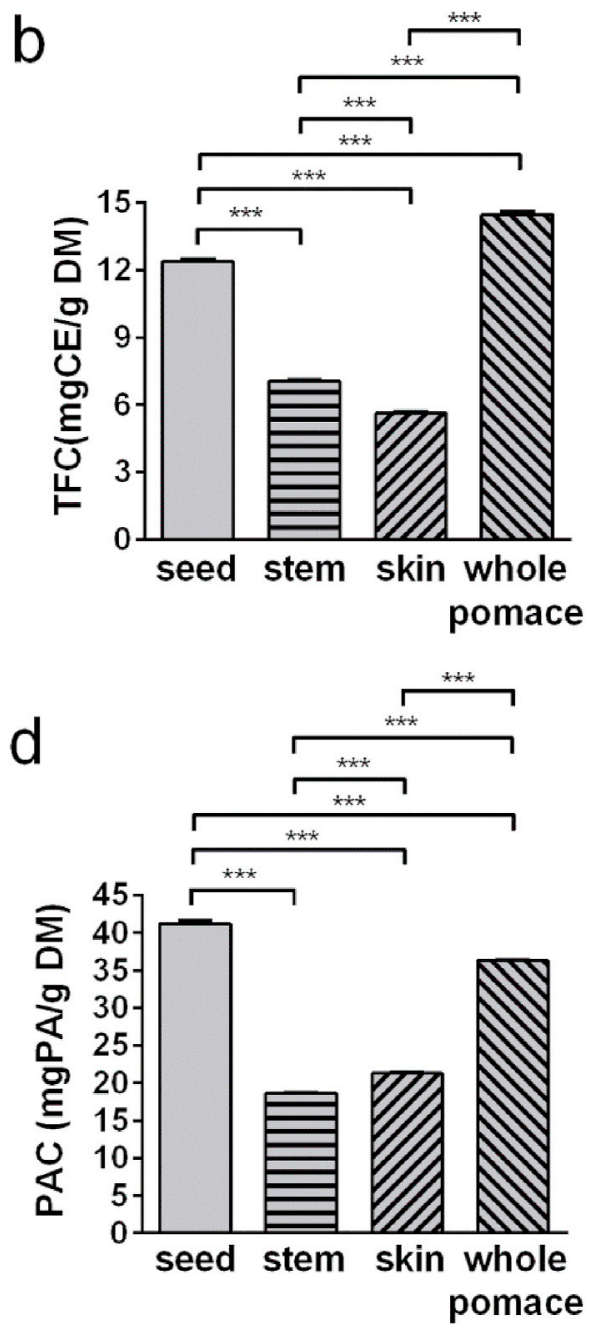

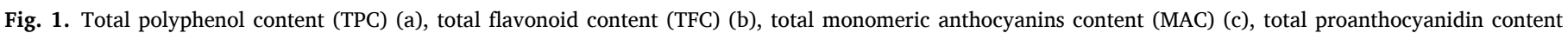
(PAC) (d) of analysed samples. The bars with *** symbol are significantly different according to $t$-test, $p<0.05$.

that ethyl gallate stimulates the production of prostagladin $\mathrm{E}_{2}$ in vitro and in vivo, that partly contributes to the proinflammatory and health beneficial effects of Longan and Litchi fruits (Wang, Sui, Ding, \& Zhu, 2018). In the aqueous extract of whole grape pomace, gallic acid hexoside isomers, di- and hydroxybenzoic acid hexosides and ethyl gallate accounted for $89.9 \%$ of the total detected hydroxybenzoic acid and its derivatives. Hydroxycinnamic acids and derivatives were presented in the content of about $50 \mathrm{mg} / \mathrm{kg}$ DM in AGP extracts of skin, stem and whole pomace and lower than $5 \mathrm{mg} / \mathrm{kg}$ DM in the AGP seed extract. Most of the detected hydroxybenzoic acids and derivatives (gallic acid hexoside isomers, gallic acid dihexoside, hydroxy- and dihydroxybensoic acid hexoside, galloyl-hexahydroxydiphenic acid-hexose, ethyl gallate, vanillic acid) in AGP extracts of Prokupac variety hasn' $t$ been reported in the PCs extracts of this variety so far.

Flavan 3-ols and proanthocyanidins represented $47.5 \%$ of all detected PCs. Procyanidin oligomers such as dimers and trimers dominated (75.5\% of total flavan 3-ols and procyanidins) compared to the monomeric flavan 3-ols (19.4\% of total flavan 3-ols and procyanidins), among which only catechin $(159.7 \pm 5.63 \mathrm{mg} \mathrm{CE} / \mathrm{kg} \mathrm{DM})$ and epicatechin $(114.0 \pm 5.38 \mathrm{mg} \mathrm{CE} / \mathrm{kg} \mathrm{DM})$ were identified. The most abundant procyanidin oligomers in the AGP seed extract were procyanidin dimer $\mathrm{B}$ type isomers, then procyanidins trimer $\mathrm{B}$ type isomers and procyanidin gallate isomers in the quantity of $34.3 \%, 24.4 \%$ and $15.3 \%$ of total flavan 3-ols and procyanidins, respectively. Significantly lower content of flavan 3-ols and proanthocyanidins was found in the AGP extracts of whole GP and stem (lower than $8 \%$ and 5\% of total PCs, respectively), while in the AGP skin extract they were present in about $8 \mathrm{mg} / \mathrm{kg}$ of DM. Similar results for the methanolic grape pomace seed and skin extracts were recorded by Peixoto et al. (2018). Zdunić et al. (2019) observed the dominant presence of catechins, proanthocyanidins and proanthocyanidins gallate among PCs extracted by $50 \%$ methanol from grape seeds of different Prokupac clones, but the presence of procyanidin dimer B type digallate isomers were not identified. These isomers were detected for the first time in this variety in AGP extracts of seed, steam and whole pomace in range of $0.7-21.7 \mathrm{mg} \mathrm{CE} / \mathrm{kg}$ DM. Higher content of oligomeric proanthocyanidins compared to the monomers in methanolic extracts of grape pomace seeds was also observed by Peixoto et al. (2018) and Pešić et al. (2019), whereas Kammerer et al. (2004) reported the domination of monomer flavan 3-ols in methanolic extract of grape pomace seed of the white grape cultivar Weisser Riesling.

In contrast to hydoxybenzoic acid derivatives and proanthocyanidins, as predominant GP seeds components, flavonol aglycones and glycosides were recorded in the content of around $1 \%$ of total PCs. On the other hand, these compounds prevailed in the AGP skin $(41.1 \%$ of total PCs) and stem (35.2\% of total PCs) extracts. Most of the identified flavonols in the AGP skin, stem and whole GP extracts were in the form of glycosides of quercetin, isohramnetin, myricetin, kaempferol, syringetin, aromadendrin and laricitrin, which is consistent with the previously reported results of Drosou et al. (2015) and Amico et al. (2004) for the ethanolic and methanolic grape pomace extracts from Greek and 
Table 1

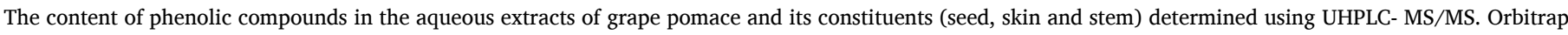
(results are expressed as $\mathrm{mg} / \mathrm{kg}$ of DM). The mean, expected retention time $\left(t_{\mathrm{R}}\right)$, molecular formula, calculated mass and exact mass are presented.

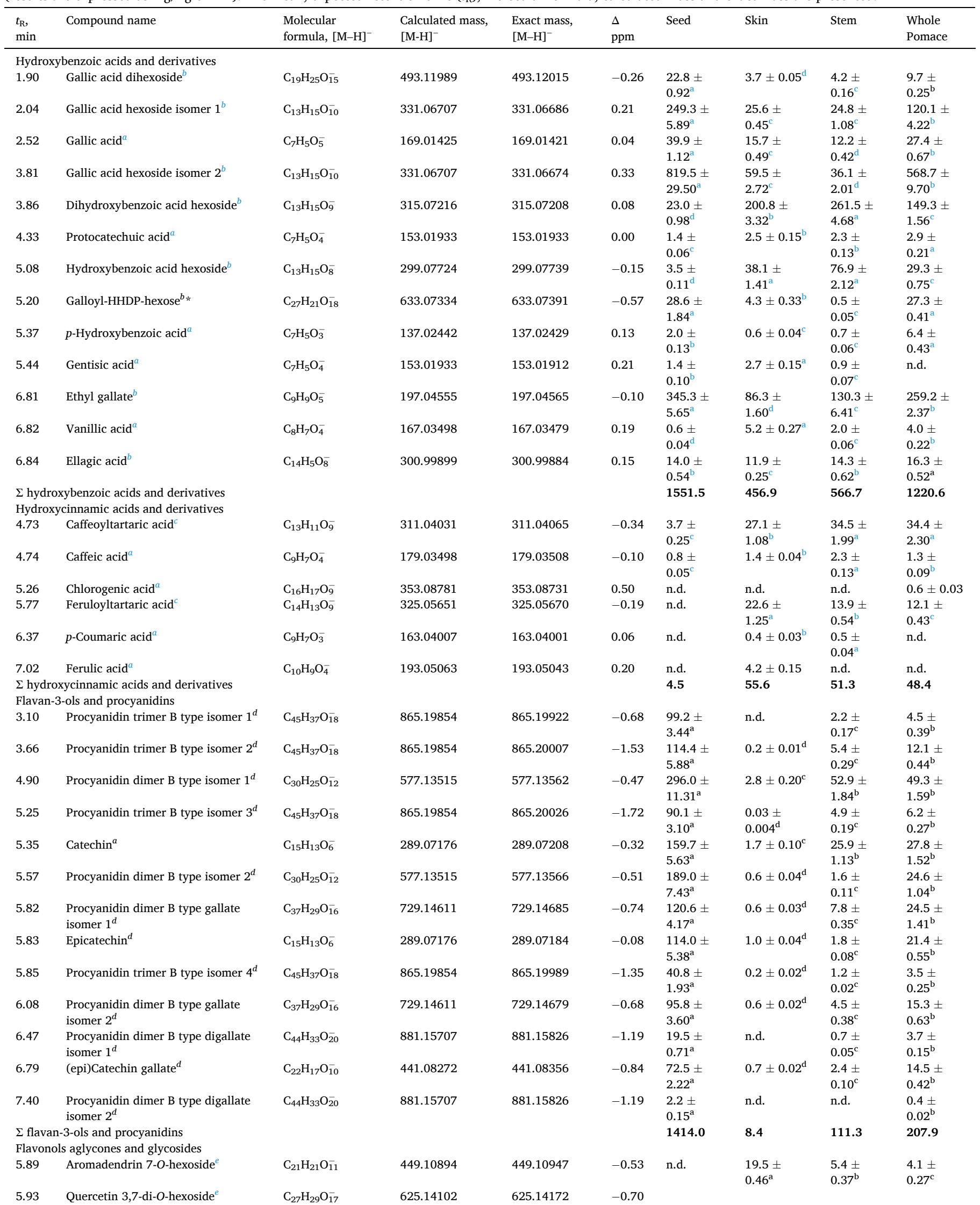


Table 1 (continued)

\begin{tabular}{|c|c|c|c|c|c|c|c|c|c|}
\hline $\begin{array}{l}t_{\mathrm{R}} \\
\min \end{array}$ & Compound name & $\begin{array}{l}\text { Molecular } \\
\text { formula, }[\mathrm{M}-\mathrm{H}]^{-}\end{array}$ & $\begin{array}{l}\text { Calculated mass, } \\
{[\mathrm{M}-\mathrm{H}]^{-}}\end{array}$ & $\begin{array}{l}\text { Exact mass, } \\
{[\mathrm{M}-\mathrm{H}]^{-}}\end{array}$ & $\begin{array}{l}\Delta \\
\mathrm{ppm}\end{array}$ & Seed & Skin & Stem & $\begin{array}{l}\text { Whole } \\
\text { Pomace }\end{array}$ \\
\hline & & & & & & $\begin{array}{l}0.7 \pm \\
0.05^{\mathrm{d}}\end{array}$ & $\begin{array}{l}66.9 \pm \\
1.92^{\mathrm{a}}\end{array}$ & $\begin{array}{l}24.0 \pm \\
1.01^{\mathrm{b}}\end{array}$ & $\begin{array}{l}13.6 \pm \\
0.25^{\mathrm{c}}\end{array}$ \\
\hline 6.22 & Myricetin 3-O-hexoside $^{e}$ & $\mathrm{C}_{21} \mathrm{H}_{19} \mathrm{O}_{13}^{-}$ & 479.08311 & 479.08374 & -0.63 & n.d. & n.d. & $\begin{array}{l}1.5 \pm \\
0.08^{\mathrm{a}}\end{array}$ & $\begin{array}{l}0.4 \pm \\
0.02^{\mathrm{b}}\end{array}$ \\
\hline 6.42 & Quercetin 3-O-rutinoside $^{a}$ & $\mathrm{C}_{27} \mathrm{H}_{29} \mathrm{O}_{16}^{-}$ & 609.14611 & 609.14575 & 0.36 & n.d. & $\begin{array}{l}38.6 \pm \\
1.47^{\mathrm{a}}\end{array}$ & $\begin{array}{l}14.6 \pm \\
0.72^{\mathrm{b}}\end{array}$ & $\begin{array}{l}11.0 \pm \\
0.42^{\mathrm{c}}\end{array}$ \\
\hline 6.70 & Laricitrin 3-O-hexoside $^{e}$ & $\mathrm{C}_{22} \mathrm{H}_{21} \mathrm{O}_{13}^{-}$ & 493.09876 & 493.09879 & -0.03 & $\begin{array}{l}0.7 \pm \\
0.04^{\mathrm{d}}\end{array}$ & $\begin{array}{l}649.5 \pm \\
7.94^{\mathrm{a}}\end{array}$ & $\begin{array}{l}375.9 \pm \\
7.27^{\mathrm{b}}\end{array}$ & $\begin{array}{l}289.0 \pm \\
5.09^{c}\end{array}$ \\
\hline 6.72 & Quercetin 3-O-hexuronide ${ }^{e}$ & $\mathrm{C}_{21} \mathrm{H}_{17} \mathrm{O}_{13}^{-}$ & 477.06692 & 477.06793 & -1.01 & $\begin{array}{l}0.5 \pm \\
0.04^{\mathrm{d}}\end{array}$ & $\begin{array}{l}41.0 \pm \\
1.88^{\mathrm{a}}\end{array}$ & $\begin{array}{l}25.1 \pm \\
0.97^{\mathrm{b}}\end{array}$ & $\begin{array}{l}14.0 \pm \\
0.41^{c}\end{array}$ \\
\hline 6.74 & Quercetin 3-O-glucoside ${ }^{a}$ & $\mathrm{C}_{21} \mathrm{H}_{19} \mathrm{O}_{12}^{-}$ & 463.08820 & 463.08920 & -1.00 & $\begin{array}{l}0.1 \pm \\
0.01^{d}\end{array}$ & $\begin{array}{l}14.7 \pm \\
0.98^{\mathrm{a}}\end{array}$ & $\begin{array}{l}6.8 \pm \\
0.49^{b}\end{array}$ & $\begin{array}{l}3.9 \pm \\
0.23^{\mathrm{c}}\end{array}$ \\
\hline 7.05 & Quercetin 3-O-rhamnoside ${ }^{a}$ & $\mathrm{C}_{21} \mathrm{H}_{19} \mathrm{O}_{11}^{-}$ & 447.09329 & 447.09357 & -0.28 & $\begin{array}{l}3.4 \pm \\
0.14^{d}\end{array}$ & $\begin{array}{l}98.6 \pm \\
2.85^{\mathrm{a}}\end{array}$ & $\begin{array}{l}37.6 \pm \\
1.09^{\mathrm{b}}\end{array}$ & $\begin{array}{l}31.3 \pm \\
1.52^{\mathrm{c}}\end{array}$ \\
\hline 7.12 & Syringetin 3-O-hexoside ${ }^{e}$ & $\mathrm{C}_{23} \mathrm{H}_{23} \mathrm{O}_{13}^{-}$ & 507.11441 & 507.11493 & -0.52 & $\begin{array}{l}0.1 \pm \\
0.01^{\mathrm{d}}\end{array}$ & $\begin{array}{l}15.5 \pm \\
0.93^{\mathrm{a}}\end{array}$ & $\begin{array}{l}7.1 \pm \\
0.15^{\mathrm{b}}\end{array}$ & $\begin{array}{l}4.2 \pm \\
0.15^{c}\end{array}$ \\
\hline 7.15 & Kaempferol 3-O-glucoside ${ }^{a}$ & $\mathrm{C}_{21} \mathrm{H}_{19} \mathrm{O}_{11}^{-}$ & 447.09329 & 447.09406 & -0.77 & $\begin{array}{l}0.3 \pm \\
0.02^{\mathrm{d}}\end{array}$ & $\begin{array}{l}27.6 \pm \\
1.68^{\mathrm{a}}\end{array}$ & $\begin{array}{l}9.3 \pm \\
0.35^{b}\end{array}$ & $\begin{array}{l}7.8 \pm \\
0.29^{c}\end{array}$ \\
\hline 7.26 & Isorhamnetin 3-O-glucoside ${ }^{a}$ & $\mathrm{C}_{22} \mathrm{H}_{21} \mathrm{O}_{12}^{-}$ & 477.10385 & 477.10461 & -0.76 & $\begin{array}{l}2.9 \pm \\
0.14^{d}\end{array}$ & $\begin{array}{l}58.8 \pm \\
3.20^{\mathrm{b}}\end{array}$ & $\begin{array}{l}153.8 \pm \\
5.57^{\mathrm{a}}\end{array}$ & $\begin{array}{l}11.8 \pm \\
0.20^{\mathrm{c}}\end{array}$ \\
\hline 7.32 & Isorhamnetin 3-O-hexuronide ${ }^{e}$ & $\mathrm{C}_{22} \mathrm{H}_{19} \mathrm{O}_{13}^{-}$ & 491.08311 & 491.08371 & -0.60 & n.d. & $5.4 \pm 0.23^{\mathrm{b}}$ & $\begin{array}{l}8.9 \pm \\
0.64^{\mathrm{a}}\end{array}$ & $\begin{array}{l}3.3 \pm \\
0.18^{\mathrm{c}}\end{array}$ \\
\hline 7.98 & Aromodedrin $^{e}$ & $\mathrm{C}_{15} \mathrm{O}_{11} \mathrm{O}_{6}^{-}$ & 287.05611 & 287.05606 & 0.05 & $\begin{array}{l}5.4 \pm \\
0.17^{d}\end{array}$ & $224.9 \pm 7^{\mathrm{a}}$ & $\begin{array}{l}101.5 \pm \\
4.61^{b}\end{array}$ & $\begin{array}{l}33.8 \pm \\
1.13^{\mathrm{c}}\end{array}$ \\
\hline 8.79 & Quercetin $^{a}$ & $\mathrm{C}_{15} \mathrm{H}_{9} \mathrm{O}_{7}^{-}$ & 301.03537 & 301.03500 & 0.37 & $\begin{array}{l}0.1 \pm \\
0.014^{\mathrm{d}}\end{array}$ & $8.9 \pm 0.54^{\mathrm{a}}$ & $\begin{array}{l}2.8 \pm \\
0.16^{\mathrm{b}}\end{array}$ & $\begin{array}{l}1.9 \pm \\
0.06^{c}\end{array}$ \\
\hline 9.73 & Kaempferol $^{a}$ & $\mathrm{C}_{15} \mathrm{H}_{9} \mathrm{O}_{6}^{-}$ & 285.04046 & 285.04019 & 0.27 & $\begin{array}{l}9.1 \pm \\
0.21^{\mathrm{d}}\end{array}$ & $\begin{array}{l}20.8 \pm \\
0.83^{\mathrm{a}}\end{array}$ & $\begin{array}{l}11.8 \pm \\
0.30^{\mathrm{b}}\end{array}$ & $\begin{array}{l}10.7 \pm \\
0.39^{c}\end{array}$ \\
\hline 9.95 & Isorhamnetin $^{a}$ & $\mathrm{C}_{16} \mathrm{H}_{11} \mathrm{O}_{7}^{-}$ & 315.05103 & 315.05078 & 0.25 & $\begin{array}{l}9.1 \pm \\
0.25^{c}\end{array}$ & $\begin{array}{l}20.8 \pm \\
0.26^{\mathrm{a}}\end{array}$ & $\begin{array}{l}11.8 \pm \\
0.89^{\mathrm{b}}\end{array}$ & $\begin{array}{l}10.7 \pm \\
0.04^{\mathrm{b}}\end{array}$ \\
\hline \multicolumn{2}{|c|}{$\begin{array}{l}\Sigma \text { flavonols aglycones and glycosides } \\
\text { Stilbenoids }\end{array}$} & & & & & 32.4 & 1311.3 & 797.8 & 451.3 \\
\hline 6.62 & Resveratrol $^{a}$ & $\mathrm{C}_{14} \mathrm{H}_{11} \mathrm{O}_{3}^{-}$ & 227.07137 & 227.07121 & 0.16 & n.d. & $0.6 \pm 0.03^{c}$ & $\begin{array}{l}3.1 \pm \\
0.11^{\mathrm{a}}\end{array}$ & $\begin{array}{l}0.7 \pm \\
0.04^{\mathrm{b}}\end{array}$ \\
\hline 7.35 & Resveratrol 3-O-glucoside ${ }^{a}$ & $\mathrm{C}_{20} \mathrm{H}_{21} \mathrm{O}_{8}^{-}$ & 389.12419 & 389.12463 & -0.44 & n.d. & n.d. & $\begin{array}{l}2.4 \pm \\
0.14^{\mathrm{a}}\end{array}$ & $\begin{array}{l}0.2 \pm \\
0.01^{\mathrm{b}}\end{array}$ \\
\hline 8.97 & Resveratrol dimer isomer $1^{f}$ & $\mathrm{C}_{28} \mathrm{H}_{21} \mathrm{O}_{6}^{-}$ & 453.13436 & 453.13486 & -0.50 & n.d. & $4.8 \pm 0.16^{\mathrm{c}}$ & $\begin{array}{l}29.4 \pm \\
1.54^{\mathrm{a}}\end{array}$ & $\begin{array}{l}6.3 \pm \\
0.17^{\mathrm{b}}\end{array}$ \\
\hline 8.39 & Resveratrol tetramer isomer $\mathbf{1}^{f}$ & $\mathrm{C}_{56} \mathrm{H}_{41} \mathrm{O}_{12}^{-}$ & 905.26035 & 905.26105 & -0.70 & $\begin{array}{l}1.0 \pm \\
0.045^{\mathrm{d}}\end{array}$ & $\begin{array}{l}13.6 \pm \\
0.33^{c}\end{array}$ & $\begin{array}{l}88.1 \pm \\
2.64^{\mathrm{a}}\end{array}$ & $\begin{array}{l}32.2 \pm \\
1.42^{\mathrm{b}}\end{array}$ \\
\hline 8.64 & Resveratrol tetramer isomer $2^{f}$ & $\mathrm{C}_{56} \mathrm{H}_{41} \mathrm{O}_{12}^{-}$ & 905.26035 & 905.26080 & -0.45 & $\begin{array}{l}1.8 \pm \\
0.13^{\mathrm{d}}\end{array}$ & $\begin{array}{l}26.7 \pm \\
1.79^{c}\end{array}$ & $\begin{array}{l}160.7 \pm \\
7.13^{\mathrm{a}}\end{array}$ & $\begin{array}{l}53.0 \pm \\
1.57^{\mathrm{b}}\end{array}$ \\
\hline 9.17 & Resveratrol dimer isomer $2^{f}$ & $\mathrm{C}_{28} \mathrm{H}_{21} \mathrm{O}_{6}^{-}$ & 453.13436 & 453.13455 & -0.19 & n.d. & $4.6 \pm 0.37^{\mathrm{b}}$ & $\begin{array}{l}33.7 \pm \\
1.99^{\mathrm{a}}\end{array}$ & $\begin{array}{l}4.1 \pm \\
0.16^{\mathrm{b}}\end{array}$ \\
\hline 9.24 & Resveratrol trimer isomer $1^{f}$ & $\mathrm{C}_{42} \mathrm{H}_{31} \mathrm{O}_{9}^{-}$ & 679.19736 & 679.19653 & 0.83 & n.d. & $5.5 \pm 0.4^{\mathrm{c}}$ & $\begin{array}{l}49.2 \pm \\
1.58^{\mathrm{a}}\end{array}$ & $\begin{array}{l}10.3 \pm \\
0.56^{\mathrm{b}}\end{array}$ \\
\hline 9.55 & Resveratrol trimer (like $\alpha$-viniferin) ${ }^{f}$ & $\mathrm{C}_{42} \mathrm{H}_{29} \mathrm{O}_{9}^{-}$ & 677.18171 & 677.18140 & 0.31 & n.d. & $0.7 \pm 0.04^{c}$ & $\begin{array}{l}17.1 \pm \\
1.12^{\mathrm{a}}\end{array}$ & $\begin{array}{l}2.2 \pm \\
0.14^{\mathrm{b}}\end{array}$ \\
\hline 9.72 & Resveratrol trimer isomer $2^{f}$ & $\mathrm{C}_{42} \mathrm{H}_{31} \mathrm{O}_{9}^{-}$ & 679.19736 & 679.19696 & 0.40 & n.d. & $1.2 \pm 0.06^{\mathrm{c}}$ & $\begin{array}{l}13.5 \pm \\
0.25^{\mathrm{a}}\end{array}$ & $\begin{array}{l}2.0 \pm \\
0.08^{\mathrm{b}}\end{array}$ \\
\hline$\Sigma$ stilb & loids & & & & & 2.8 & 57.7 & 397.0 & 111.0 \\
\hline \multicolumn{10}{|c|}{ Anthocyanins } \\
\hline 4.64 & Delphinidin 3-O-glucoside ${ }^{a}$ & $\mathrm{C}_{21} \mathrm{H}_{21} \mathrm{O}_{12}^{+}$ & 465.10275 & 465.09958 & 3.17 & n.d. & $\begin{array}{l}92.8 \pm \\
2.57^{\mathrm{a}}\end{array}$ & $\begin{array}{l}16.7 \pm \\
0.56^{\mathrm{c}}\end{array}$ & $\begin{array}{l}44.5 \pm \\
2.12^{\mathrm{b}}\end{array}$ \\
\hline 4.65 & Malvidin 3,5-di-O-glucoside ${ }^{a}$ & $\mathrm{C}_{29} \mathrm{H}_{35} \mathrm{O}_{17}^{+}$ & 655.18688 & 655.18213 & 4.75 & n.d. & $0.5 \pm 0.02^{\mathrm{a}}$ & n.d. & $\begin{array}{l}0.4 \pm \\
0.02^{\mathrm{b}}\end{array}$ \\
\hline 4.78 & Cyanidin 3-O-glucoside ${ }^{a}$ & $\mathrm{C}_{21} \mathrm{H}_{21} \mathrm{O}_{11}^{+}$ & 449.10784 & 449.10425 & 3.59 & n.d. & $\begin{array}{l}17.3 \pm \\
0.83^{\mathrm{a}}\end{array}$ & $\begin{array}{l}13.0 \pm \\
0.85^{\mathrm{b}}\end{array}$ & $\begin{array}{l}9.0 \pm \\
0.26^{c}\end{array}$ \\
\hline 4.82 & Cyanidin 3-O-sambubioside $^{a}$ & $\mathrm{C}_{26} \mathrm{H}_{29} \mathrm{O}_{15}^{+}$ & 581.15010 & 581.14541 & 4.69 & n.d. & n.d. & $\begin{array}{l}0.6 \pm \\
0.04^{\mathrm{a}}\end{array}$ & $\begin{array}{l}0.5 \pm \\
0.03^{\mathrm{b}}\end{array}$ \\
\hline 5.07 & Petunidin 3-O-hexoside ${ }^{g}$ & $\mathrm{C}_{22} \mathrm{H}_{23} \mathrm{O}_{12}^{+}$ & 479.11840 & 479.11465 & 3.75 & n.d. & $\begin{array}{l}114.8 \pm \\
5.11^{\mathrm{a}}\end{array}$ & n.d. & $\begin{array}{l}42.2 \pm \\
1.88^{\mathrm{b}}\end{array}$ \\
\hline 5.04 & Cyanidin 3-O-arabinoside ${ }^{a}$ & $\mathrm{C}_{20} \mathrm{H}_{19} \mathrm{O}_{10}^{+}$ & 419.09727 & 419.09308 & 4.19 & n.d. & $0.6 \pm 0.03^{\mathrm{b}}$ & $\begin{array}{l}4.8 \pm \\
0.17^{\mathrm{a}}\end{array}$ & n.d. \\
\hline 5.15 & Pelargonidin 3-O-glucoside ${ }^{a}$ & $\mathrm{C}_{21} \mathrm{H}_{21} \mathrm{O}_{10}^{+}$ & 433.11292 & 433.10864 & 4.28 & n.d. & n.d. & n.d. & $0.2 \pm 0.02$ \\
\hline 5.42 & Peonidin 3-O-glucoside ${ }^{a}$ & $\mathrm{C}_{22} \mathrm{H}_{23} \mathrm{O}_{11}^{+}$ & 463.12349 & 463.12054 & 2.95 & n.d. & $\begin{array}{l}301.0 \pm \\
6.49^{\mathrm{a}}\end{array}$ & $\begin{array}{l}111.4 \pm \\
3.52^{\mathrm{c}}\end{array}$ & $\begin{array}{l}159.3 \pm \\
2.68^{\mathrm{b}}\end{array}$ \\
\hline 5.47 & Malvidin 3-O-glucoside ${ }^{a}$ & $\mathrm{C}_{23} \mathrm{H}_{25} \mathrm{O}_{12}^{+}$ & 493.13405 & 493.13107 & 2.98 & n.d. & $\begin{array}{l}600.1 \pm \\
11.09^{\mathrm{a}}\end{array}$ & $\begin{array}{l}194.7 \pm \\
6.14^{\mathrm{c}}\end{array}$ & $\begin{array}{l}250.4 \pm \\
6.71^{\mathrm{b}}\end{array}$ \\
\hline 5.97 & Malvidin 3-O-hexoside-acetaldehyde ${ }^{g}$ & $\mathrm{C}_{25} \mathrm{H}_{25} \mathrm{O}_{12}^{+}$ & 517.13405 & 517.13007 & 3.98 & n.d. & $\begin{array}{l}12.8 \pm \\
0.81^{\mathrm{a}}\end{array}$ & n.d. & $\begin{array}{l}4.0 \pm \\
0.04^{\mathrm{b}}\end{array}$ \\
\hline 6.30 & Peonidin 3-O-(6" -acetyl)hexoside ${ }^{g}$ & $\mathrm{C}_{24} \mathrm{H}_{25} \mathrm{O}_{12}^{+}$ & 505.13405 & 505.13010 & 3.95 & n.d. & $1.0 \pm 0.04^{\mathrm{a}}$ & n.d. & $\begin{array}{l}0.2 \pm \\
0.01^{\mathrm{b}}\end{array}$ \\
\hline 6.24 & $\begin{array}{l}\text { Malvidin 3-O-hexoside- }(8,8)- \\
\text { methylmethyne-(epi)catechin }\end{array}$ & $\mathrm{C}_{40} \mathrm{H}_{41} \mathrm{O}_{18}^{+}$ & 809.22874 & 809.22378 & 4.96 & n.d. & $4.1 \pm 0.19^{b}$ & n.d. & $\begin{array}{l}11.8 \pm \\
0.32^{\mathrm{a}}\end{array}$ \\
\hline
\end{tabular}


Table 1 (continued)

\begin{tabular}{|c|c|c|c|c|c|c|c|c|c|}
\hline $\begin{array}{l}t_{\mathrm{R}} \\
\min \end{array}$ & Compound name & $\begin{array}{l}\text { Molecular } \\
\text { formula, }[\mathrm{M}-\mathrm{H}]^{-}\end{array}$ & $\begin{array}{l}\text { Calculated mass, } \\
{[\mathrm{M}-\mathrm{H}]^{-}}\end{array}$ & $\begin{array}{l}\text { Exact mass, } \\
{[\mathrm{M}-\mathrm{H}]^{-}}\end{array}$ & $\begin{array}{l}\Delta \\
\mathrm{ppm}\end{array}$ & Seed & Skin & Stem & $\begin{array}{l}\text { Whole } \\
\text { Pomace }\end{array}$ \\
\hline 6.32 & Malvidin 3-O-(6"-acetyl)hexoside ${ }^{g}$ & $\mathrm{C}_{25} \mathrm{H}_{27} \mathrm{O}_{13}^{+}$ & 535.14462 & 535.14136 & 3.26 & n.d. & $4.4 \pm 0.23^{\mathrm{a}}$ & n.d. & $\begin{array}{l}1.2 \pm \\
0.07^{\mathrm{b}}\end{array}$ \\
\hline 6.44 & $\begin{array}{l}\text { Delphinidin 3-O-(6" }-p \text {-coumaroyl }) \\
\text { hexoside }^{g}\end{array}$ & $\mathrm{C}_{30} \mathrm{H}_{27} \mathrm{O}_{14}^{+}$ & 611.13953 & 611.13483 & 4.70 & n.d. & $5.4 \pm 0.21^{\mathrm{a}}$ & n.d. & $\begin{array}{l}3.2 \pm \\
0.16^{\mathrm{b}}\end{array}$ \\
\hline 6.67 & Malvidin 3-O-(6"-caffeoyl)hexoside ${ }^{g}$ & $\mathrm{C}_{32} \mathrm{H}_{31} \mathrm{O}_{15}^{+}$ & 655.16575 & 655.16095 & 4.80 & n.d. & $8.2 \pm 0.35^{\mathrm{a}}$ & n.d. & $\begin{array}{l}2.9 \pm \\
0.16^{\mathrm{b}}\end{array}$ \\
\hline 6.73 & $\begin{array}{l}\text { Petunidin 3-O-(6" }-p \text {-coumaroyl }) \\
\text { hexoside }^{g}\end{array}$ & $\mathrm{C}_{31} \mathrm{H}_{29} \mathrm{O}_{14}^{+}$ & 625.15518 & 625.15045 & 4.73 & n.d. & $\begin{array}{l}12.0 \pm \\
0.35^{\mathrm{a}}\end{array}$ & n.d. & $\begin{array}{l}5.3 \pm \\
0.30^{\mathrm{b}}\end{array}$ \\
\hline 7.03 & $\begin{array}{l}\text { Peonidin 3-O-(6" }-p \text {-coumaroyl) } \\
\text { hexoside }^{g}\end{array}$ & $\mathrm{C}_{31} \mathrm{H}_{29} \mathrm{O}_{13}^{+}$ & 609.16027 & 609.15723 & 3.04 & n.d. & $\begin{array}{l}26.7 \pm \\
1.71^{\mathrm{a}}\end{array}$ & n.d. & $\begin{array}{l}15.0 \pm \\
0.73^{\mathrm{b}}\end{array}$ \\
\hline 7.10 & $\begin{array}{l}\left.\text { Malvidin 3-O-(6" } 6^{\prime \prime}-\text {-coumaroyl }\right) \\
\text { hexoside }^{g}\end{array}$ & $\mathrm{C}_{32} \mathrm{H}_{31} \mathrm{O}_{14}^{+}$ & 639.17083 & 639.16595 & 4.88 & n.d. & $\begin{array}{l}102.1 \pm \\
4.38^{\mathrm{a}}\end{array}$ & n.d. & $\begin{array}{l}44.6 \pm \\
1.89^{\mathrm{b}}\end{array}$ \\
\hline \multicolumn{6}{|c|}{$\Sigma$ anthocyanins } & n.d. & 1303.6 & 341.3 & 594.7 \\
\hline \multicolumn{6}{|c|}{$\Sigma$ phenolic compounds } & 3005.2 & 3193.5 & 2265.3 & 2633.8 \\
\hline
\end{tabular}

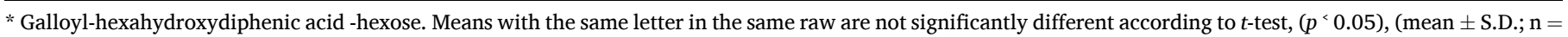

3); 'n.d.' stands for not detected.

a Quantified using corresponding standards.

b Expressed as p-hydroxybenzoic acid equivalents.

c Expressed as caffeic acid equivalents.

d Expressed as catechin equivalents.

e Expressed as quercetin equivalents.

${ }^{\mathrm{f}}$ Expressed as resveratrol equivalents and.

$\mathrm{g}$ Expressed as malvidin 3-O-glucoside equivalents.

Italian red grape varieties, respectively. Among the detected flavonols, laricitrin 3-O-hexoside showed the highest content in the AGP extracts of skin, stem and whole GP, $649.5 \pm 7.94,375.9 \pm 7.27$ and $289.0 \pm 5.9$ $\mathrm{mg} \mathrm{QE} / \mathrm{kg}$ of DM, respectively. Furthermore, significant content of isohramnetin 3-O-glucoside (153.8 $\pm 5.57 \mathrm{mg} \mathrm{QE} / \mathrm{kg} \mathrm{DM})$ and quercetin 3 -O-glucoside $(98.6 \pm 2.85 \mathrm{mg} \mathrm{QE} / \mathrm{kg} \mathrm{DM})$ was observed in the AGP stem and skin extracts, respectively. Peixoto et al. (2018) showed that the dominant flavonols in the methanolic extracts of grape pomace skin and mixture of GP skin and seed were laricitrin, quercetin and syringetin glycosides. It should be mentioned that myricetin glycoside was found in a low quantity (less than 2\%) in the AGP stem and whole GP extracts, while in the AGP extracts of skin and seed it was not identified, which is consistent with the results of Peixoto et al. (2018) for methanolic extracts of grape pomace skin and seed extracts but opposite to the results presented by Drosou et al. (2015) for ethanolic extract of Agiorgitiko grape pomace. Most of the flavonols glycosides (except quercetin 3 $\mathrm{O}$-glucoside, quercetin $3 \mathrm{O}$-hexuronide and quercetin $3 \mathrm{O}$-rhamnoside) as well as aromodedrin and isorhamnetin are detected for the first time in PCs extracts of Prokupac variety in this study.

A special class of identified PCs with potential antioxidant and nutritional properties is stilbenoids, among which resveratrol was detected in its aglyconic, glycosidic and oligomeric forms. Stilbenoids were present in low content in the AGP seed extract ( $2.8 \mathrm{mg} \mathrm{RS} / \mathrm{kg} \mathrm{DM})$, while in the AGP skin and whole GP extracts were determined in the content of $57.7 \mathrm{mg}$ RS/ kg DM and $111.0 \mathrm{mg}$ RS/ $\mathrm{kg}$ DM respectively. However, they were present in significant content in the AGP stem extract, $397.0 \mathrm{mg} \mathrm{RS} / \mathrm{kg} \mathrm{DM}$, which represented $17.5 \%$ of the total quantified PCs. Among the detected stilbenoids, the resveratrol oligomers such as dimer, trimer and tetramer isomers were the most abundant and have not been reported in PCs extracts of Pokupac variety so far. Anastasiadi et al. (2012) reported the presence of high content of trans-resveratrol and $\epsilon$-viniferin in the methanolic extract of grape stem from red and white native Greek cultivars, whose total content varied from 241 to $742 \mathrm{mg} / \mathrm{kg} \mathrm{DM}$, respectively, depending on the grape variety. Furthermore, high content of $\varepsilon$-viniferin was reported in different ethanol/water bunch stems extracts of grape varieties cultivated in Argentina (81.2-1373 mg/kg DM) (Ferreyra, Bottini, \& Fontana, 2019, 2021). These results indicate that the AGP stem extract of Prokupac variety represents a good source of stilbenoids.

In this study, a total of eighteen anthocyanin derivatives were identified in AGP extracts of whole pomace, skin and stem, while in the
AGP seed extract these compounds were not detected. The most abundant compound was malvidin 3-O-glucoside $(600.1 \pm 11.09 \mathrm{mg} / \mathrm{kg} \mathrm{DM}$, $250.4 \pm 6.71 \mathrm{mg} / \mathrm{kg}$ DM and $194.7 \pm 6.14 \mathrm{mg} / \mathrm{kg}$ DM in the AGP skin, whole pomace and stem extracts, respectively) followed by peonidin 3$O$-glucoside $(301.0 \pm 6.49 \mathrm{mg} / \mathrm{kg} \mathrm{DM}, 159.3 \pm 2.68 \mathrm{mg} / \mathrm{kg} \mathrm{DM}$ and $111.4 \pm 3.52 \mathrm{mg} / \mathrm{kg} \mathrm{DM}$, respectively). The presence of cyaniding 3-Osambubioside, cyaniding 3-O-arabinoside, pelargonidin 3-O-glucoside and malvidin 3-O-hexoside-acetaldehyde in AGP extracts of skin, steam and whole GP was detected at low quantity (less than $1.5 \%$ of total detected PCs in analysed samples), but hasn't been reported in PCs extracts of Pokupac variety so far. Significantly higher content of anthocyanin derivatives was found in metanolic and ethanolic grape pomace extracts of red grape varieties (Malbec, Agiorgitiko, Cabernet Sauvignon, Merlot) studied by other authors (Antoniolli et al., 2015; Drosou et al., 2015; Pintać et al., 2018), but these authors expressed results on dry extract-basis which significantly increased the amount compared to calculation of the content on dry pomace-basis due to low extract yield (from 2.8\% to 24.4\% (Drosou et al., 2015), or 16.1\% (Antoniolli et al., 2015)). Furthermore, it should be taken into account that Prokupac grape variety contains significantly less anthocyanins compared to other red grape varieties (Mitić et al., 2012) and differences in sample preparation procedure carried out in the analysis. Namely, in this study, methanol extracts of grape pomace were evaporated, resuspended in milliQ water and after filtration through $0.45 \mu \mathrm{m}$ syringe filters subjected to UHPLC-Orbitrap $\mathrm{MS}^{4}$ analysis whereas other authors (Antoniolli et al., 2015; Drosou et al., 2015; Pintać et al., 2018) analysed methanol/water or ethanol/water grape pomace extracts. However, Peixoto et al. (2018) and Amico et al. (2004) reported significantly lower content of anthocyanins in the $80 \%$ acidified methanol extracts of grape pomace skin collected after production of Portuguese and Sicilian red grape wines, respectively, compared to our results. The presence of anthocyanins in the AGP extract of the stem was probably a consequence of their adsorption on the stem due to intensive contact with the grape skin during mashing and vinification. Also, coumaroyl, acetyl and caffeoyl anthocyanin derivatives were found at low quantity (lower than $5 \%$ of total anthocyanins) in the tested AGP extracts, except for coumaroylhexoside derivatives of malvidin and peonidin in the AGP skin $(102.1 \pm 4.38 \mathrm{mg}$ M3G/kg DM and $26.7 \pm 1.71 \mathrm{mg}$ M3G/kg DM, respectively) and whole grape pomace ( $44.6 \pm 1.89 \mathrm{mg} \mathrm{M} 3 \mathrm{G} / \mathrm{kg}$ DM and $15.0 \pm 0.73 \mathrm{mg}$ M3G $/ \mathrm{kg} \mathrm{DM}$, respectively) extracts. The presence of these derivatives in the ethanolic and methanolic grape pomace extracts 
(a)<smiles>CCCCOC(=O)c1cc(O)c([O-])c(O)c1</smiles>

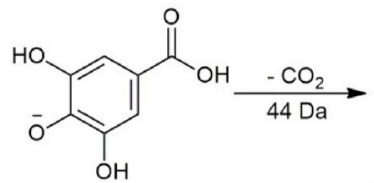<smiles>[O-]c1c(O)cccc1O</smiles>

Molecular ion, $\mathrm{M}^{-} \mathrm{H}^{-}$ $\mathrm{C}_{9} \mathrm{H}_{9} \mathrm{O}_{5}$ $197.04555 \mathrm{~m} / \mathrm{z}$

$\mathrm{MS}^{2}$ base peak $\mathrm{C}_{7} \mathrm{H}_{5} \mathrm{O}_{5}^{-}$ $169 \mathrm{~m} / \mathrm{z}$<smiles>[Y]C(C)[18OH]</smiles><smiles>O=C(O)c1c#cc([O-])c(O)c1</smiles>

$151 \mathrm{~m} / \mathrm{z}$
$\mathrm{MS}^{3}$ base peak

$\mathrm{C}_{6} \mathrm{H}_{5} \mathrm{O}_{3}^{-}$

$125 \mathrm{~m} / \mathrm{z}$

$44 \mathrm{Da} \mid \begin{aligned} & -\mathrm{H}_{2} \mathrm{O} \\ & -\mathrm{CHCH}\end{aligned}$<smiles>[O]C1=C(O)C#C1</smiles>

$\mathrm{MS}^{4}$ base peak $\mathrm{C}_{4} \mathrm{HO}_{2}{ }^{-}$ $81 \mathrm{~m} / \mathrm{z}$

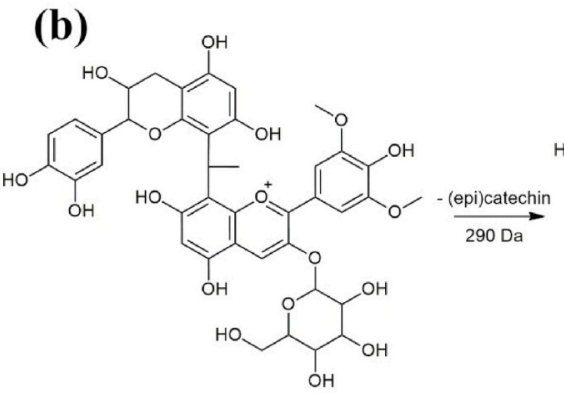
Moleculear ion, $\mathrm{M}^{*}$ $\mathrm{C}_{40} \mathrm{H}_{41} \mathrm{O}_{18}{ }^{+}$ $809.22874 \mathrm{~m} / \mathrm{z}$<smiles></smiles><smiles>C=Cc1c(O)cc(O)c2cc(OC3OC(CO)C(O)C(O)C3O)c(-c3cc(OC)c(O)c(OC)c3)cc12</smiles>
$\mathrm{MS}^{2}$ $\mathrm{C}_{25} \mathrm{H}_{27} \mathrm{O}_{12}{ }^{+}$<smiles></smiles>
$-\mathrm{CH}_{3},-\left.\mathrm{H}^{+}\right|_{16 \mathrm{Da}}$<smiles>CCC</smiles><smiles></smiles><smiles>C=Cc1c(O)cc(O)c2cc(O)c(C3=CC(OC)C(=O)C(=O)C3)cc12</smiles>
$\mathrm{MS}^{3}$ base peak

Fig. 2. Proposed fragmentation pathway of ethyl gallate (a) and proposed fragmentation pathway of malvidin-3-O-hexoside-(8,8)-methylmethyne-(epi)catechin (b).

of Nerello mascalese, Merlot, Cabernet Sauvignon, Terci, Mix and Agiorgitiko was also recorded by others (Amico et al., 2004; Drosou et al., 2015; Ribeiro et al., 2015). Furthermore, this research showed the presence of specific compound, malvidin 3-O-hexoside-(8,8)-methylmethyne-(epi)catechin, in the aqueous extracts of grape pomace skin $(4.1 \pm 0.19 \mathrm{mg} \mathrm{M} 3 \mathrm{G} / \mathrm{kg} \mathrm{DW})$ and whole grape pomace $(11.8 \pm 0.32 \mathrm{mg}$ $\mathrm{M} 3 \mathrm{G} / \mathrm{kg} \mathrm{DW}$ ). This compound is a complex of (epi)catechin and malvidin 3-O-hexoside and is formed during the aging of wine by an acetaldehyde-induced reaction. In this way, anthocyanin and flavan 3-ol molecules are linked via an ethyl (methylmethyne) group. In some papers, it has been designated as malvidin glucoside-ethyl-catechin (Zhang et al., 2020). It was previously identified only in the red grape pomace from Portuguese grape varieties (Oliveira et al., 2015) but it wasn't quantified. Proposed fragmentation pathway of this compound is presented in Fig. 2b. High content of various anthocyanin derivatives, present in the AGP skin and whole grape pomace extracts enables further valorisation and utilization of these compounds as natural food colorants or functional additives in food industry.

\subsection{Reducing power and antioxidant radical scavenging activity}

Results for antioxidant assays are presented in Fig. 3a, b, c and d. All results of the ferric reducing power for AGP extracts of seed, skin, stem and whole grape pomace ranging from 0.1 to 0.3 units of absorbance at $700 \mathrm{~nm}$ are presented in Fig. 3a. The highest value and reduction potential were noticed for the AGP seed extract, $0.279 \pm 0.001$, followed 
a

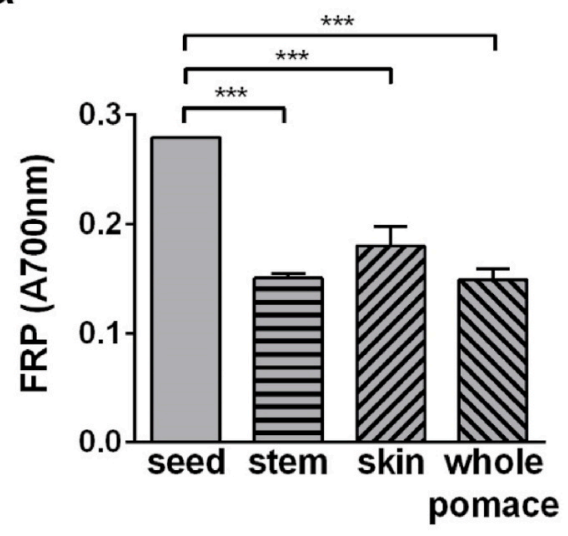

C

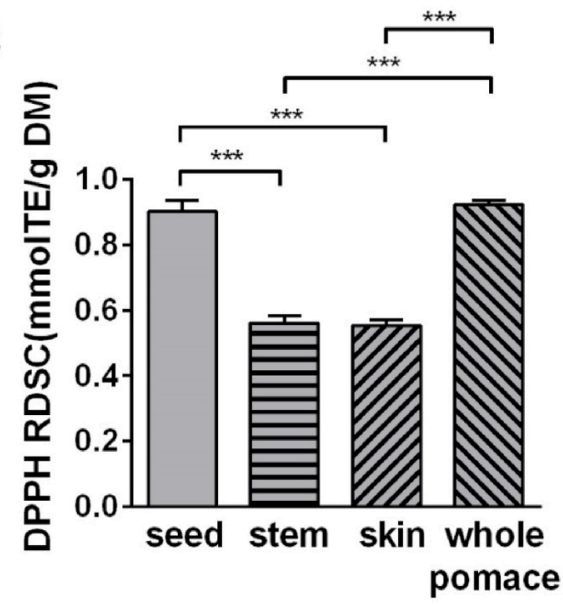

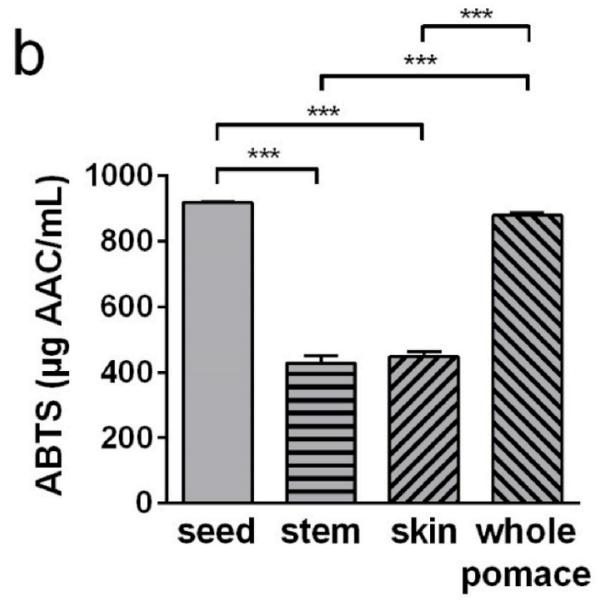

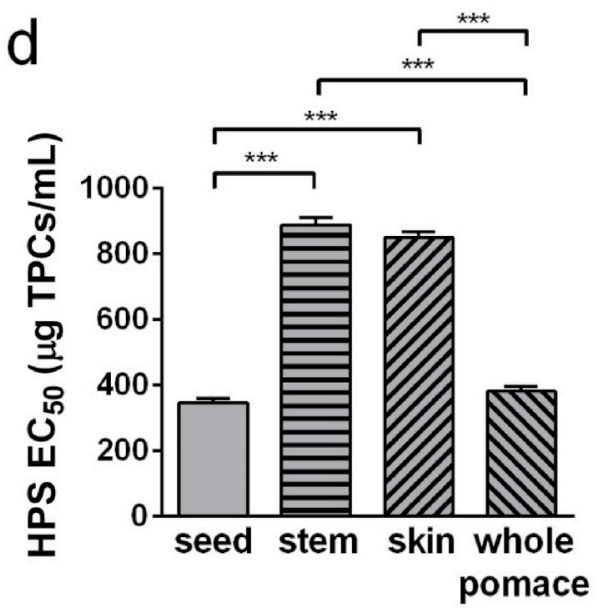

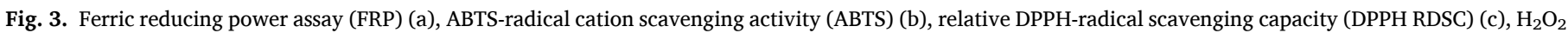
scavenging assay (HPS) (d) of analysed samples. The bars with $* * *$ symbol are significantly different according to $t$-test, $p<0.05$.

by the AGP skin, stem and whole grape pomace extracts, respectively. The correlation analysis revealed a significant positive correlation between FRP and the content of total flavan 3-ols and procyanidins estimated by UHPLC-Orbitrap MS ${ }^{4}$ analysis $(r=0.94)$.

It was already reported by Gülçin (2012) that antioxidant activity of polyphenols (PPs) depends on their extent of hydroxylation and conjugation. The positive relationship between the content of total procyanidins (monomers and dimers) in ethanolic grape pomace seed extracts from French grape varieties and their ability to reduce $\mathrm{Fe}^{3+}$ ions was observed by Ky et al. (2014).

As presented in Fig. 3b, the AGP extracts of seed and whole grape pomace showed significant ABTS $\bullet^{+}$scavenging activity of $918.7 \pm 2.67$ and $878.6 \pm 13.37 \mu \mathrm{gAC} / \mathrm{mL}$, respectively, while the values obtained for the AGP skin and stem extracts were about twice less. The main reason for these differences was the variation in the content and composition of the extracted PCs and it seems that the procyandins and phenolic acids strongly contributed to this activity. The TPC $(r=0.98)$, TFC $(r=0.95)$, PAC $(r=0.99)$ and the content of the sum of hydroxybenzoic and hydroxycinnamic acids and derivatives $(r=0.98)$ estimated by UHPLC-Orbitrap MS ${ }^{4}$ analysis were in a strong positive correlation with ABTS $\bullet^{+}$scavenging activity of tested AGP extracts. Furthermore, among phenolic acids, hydroxybenzoic acids and derivatives $(r=0.97)$, gallic acid derivatives $(r=0.97)$, especially ethyl gallate $(r=0.95)$ were the most important for ABTS radical cation scavenging activity. The positive influence of the content of total PCs or specific class of PCs in the ethanolic and water grape pomace skin, seed and whole grape pomace extracts to $\mathrm{ABTS}^{+}$radical quenching ability has been well documented in the literature (González-Paramás, Esteban-Ruano, Santos-Buelga, de Pascual-Teresa, \& Rivas-Gonzalo, 2004; Ky et al., 2014).

High-throughput relative DPPH radical scavenging capacity assay (Cheng et al., 2006) was applied in the current study. This assay uses an area under the curve for the radical scavenging capacity determination taking into account both kinetic and thermodynamic aspect of the reaction between radical and antioxidant, giving as the output results expressed as trolox equivalents per $\mu \mathrm{mol}$ of the compound or per sample dry weight in case of complex extract. Additionally, it is also significant to point out that this assay was developed and validated using extracts of pulverised Chardonnay and Pinot Noir grape seeds. Determination of DPPH RDSC value in our experiments eonducted on different grape pomace (Fig. 3c.) showed that whole GP and seed GP aqueous extracts had higher DPPH RDSC values than AGP skin and steam extracts. Obtained values, ranging between 0.55 and $0.92 \mathrm{mmol} \mathrm{TE} / \mathrm{g} \mathrm{DM}$, were comparable with the results previously reported for the DPPH RDSC of seed flours aceton extracts of Chardonnay and Pinot noir grape varieties (Cheng et al., 2006) or for acidified methanol extracts of grape skins and seeds of Meili variety (Liu, Li, Tian, Liao, \& Zhang, 2016). The relative DPPH radical scavenging capacity was in a strong positive correlation with $\mathrm{ABTS}^{+}{ }^{+}$scavenging activity of tested extracts $(r=0.99)$, thus positively correlated with the content of phenolic compounds, total flavonoids, total proantocyanidins (TPC, $r=1.00$; TFC, $r=0.98$; PAC, $r=0.97$ ), the sum of hydroxybenzoic and hydroxycinnamic acids and derivatives $(r=0.96)$, total hydroxybenzoic acids and derivatives 
$(r=0.95)$ total gallic acid derivatives $(r=0.93)$ and ethyl gallate $(r=0.93)$. This study reported the DPPH RDSC values for grape pomace samples for the first time, which would allow the direct comparison of DPPH radical scavenging capacities of grape pomace or other food samples from different laboratories with the same extraction solvent.

Hydrogen peroxide scavenging capacities of different grape pomace compounds have been determined using highly sensitive chemiluminescent method by measuring the peak values of luminescence generated in reaction of luminol and $\mathrm{H}_{2} \mathrm{O}_{2}$ in the presence or absence of grape pomace aqueous extracts. Obtained $\mathrm{IC}_{50}$ values are shown in Fig. $3 \mathrm{~d}$. All examined AGP extracts possessed the ability to scavenge $\mathrm{H}_{2} \mathrm{O}_{2}$. AGP seed extract possessed the minimal IC $\mathrm{I}_{50}$ value of $345.5 \pm 23.4 \mu \mathrm{g}$ TPCs/ $\mathrm{mL}$, showing the highest scavenging capacity. Similar capacity was recorded for the whole grape pomace aqueous extract $\left(\mathrm{IC}_{50}=381.5 \pm\right.$ $21.6 \mu \mathrm{g}$ TPCs $/ \mathrm{mL}$ ). AGP stem and skin extracts had much lower scavenging capacities $\left(\mathrm{IC}_{50}=888.7 \pm 39.8\right.$ and $\mathrm{IC}_{50}=849.3 \pm 32.6 \mu \mathrm{g}$ $\mathrm{TPCs} / \mathrm{mL}$, respectively) than AGP extracts of whole GP and seed, but without a statistically significant difference between these two samples. Moreover, the negative correlation of HPS with the content of phenolic compounds or class of PCs (TPC, $r=-0.98$; TFC, $r=-0.95$; PAC, $r=-0.99$; hydroxybenzoic and hydroxycinnamic acids and derivatives, $r=-0.97$; total hydroxybenzoic acids derivatives, $r=-0.97$; total gallic acid derivatives, $r=-0.96$ and ethyl gallate, $r=-0.95$ ) in the AGP extracts confirmed already proven high antioxidant activities of these phenolic compounds by cation ABTS and DPPH radical assays.

\subsection{Cytotoxic properties and cellular antioxidant activity}

Before testing cellular antioxidant activity it was necessary to determine non cytotoxic doses of aqueous grape pomace extracts on Caco-2 cells. For this purpose, a micro-culture tetrazolium assay (MTT) was applied and the results are presented in Fig. 4a.

From the obtained data it can be observed that none of the used extract dilutions, ranging from 0.01 to $1 \%(\sim 0.66-66 \mathrm{mg} \mathrm{TPCs} / \mathrm{mL})$ exerted statistically significant cytotoxic effect in Caco-2 cell line. Thus, the same dilutions were used for further assays of cellular antioxidant activity.

Results of cellular antioxidant activity (CAA) assay are presented in Fig. 4b. In our experiment, the $\mathrm{EC}_{50}$ value was successfully determined only for AGP skin extract (56.4 mg TPCs/mL), which is in accordance with the findings of Wolfe and Liu (2007) for aceton extracts of grape berries. For other samples we were unable to establish statistically significant and dose dependent antioxidant effects. These results could be explained most probably by the variable phenolic composition of different AGP extracts. First of all, the presence of flavonols and anthocyanins and their derivatives contributed mostly to this activity. As it can be seen from Table 1, AGP skin extract is particularly rich in quercetin, kaempferol and their glycosides, when compared to other examined AGP extracts in this study. Moreover, the correlation analysis revealed a significant positive correlation between the CAA and MAC $(r=0.93)$ as well as with the content of total anthocyanins $(r=0.90)$, total flavonoids $(r=0.98)$ and derivatives of quercetin $(r=0.92)$, kaempferol $(r=0.95)$, syringetin $(r=0.90)$, aromadendrin $(r=0.92)$, malvidin $(r=0.91)$ and petunidine $(r=0.93)$ estimated by UHPLC-Orbitrap $\mathrm{MS}^{4}$ analysis. It had been shown previously by Wolfe and Liu (2007) that certain phenolic compounds, such as quercetin or kaempferol can exert more prominent CAA effects than other PPs.

Generally speaking, it can be speculated about the mechanisms of antioxidant action of grape phenolic compounds at cellular level. According to the authors of CAA assay used in the present study, the grape PCs could quench generated radicals before they interacted with DCFH yielding fluorescent signal or with ABAP preventing radical formation. Other possible pathways are through the inhibition of lipid peroxidation, reaction with peroxyl radicals enabling propagation of other radicals or by inhibition of cellular oxidation of DCFH (Kellett et al., 2018). Nevertheless, further confirmation and more elaborate examination of the effects of grape pomace extracts on intracellular ROS production and antioxidant defence system is still necessary for making more precise conclusions.

\section{Conclusions}

Qualitative and quantitative characterization of phenolic compounds of AGP extracts of Prokupac variety determined 75 compounds (57 non-anthocyanins and 18 anthocyanins). Thirty four phenolic compounds identified and quantified in this study were not reported in the PCs extracts of Prokupac variety so far. The content of specific compound, malvidin-3-O-hexoside-(8,8)-methylmethyne-(epi)catechin, in the aqueous extracts of grape pomace skin and whole grape pomace was firstly announced and the fragmentation pathway was proposed. Additionally, considerable content of ethyl gallate was observed in all analysed samples. Also, the new data reported for these extracts in terms of cytotoxic properties and antioxidant activities (cell-based and noncell based). Procyandins (mainly a procyanidin dimers B type) and phenolic acids (predominantly hydroxybenzoic acids and derivatives), were the most abundant in the AGP seed extract and strongly contributed to the scavenging of ABTS $\bullet^{+} \mathrm{DPPH} \bullet$ and $\mathrm{H}_{2} \mathrm{O}_{2}$. On the other hand, the AGP skin extract showed the dose dependent cellular antioxidant activity on human epithelial colorectal adenocarcinoma cells. This could be attributed to the presence of flavonols and anthocyanins, mainly laricitin 3-O-hexoside and malvidin and peonidin glucosides that were dominant in the AGP skin extract. The AGP stem extract of Prokupac variety appeared to be a good source of stilbenoids.

Therefore, the utilization of Prokupac whole grape pomace, skin, seed and steam can be a cheap source of phenolic compounds suitable for the development of new functional food or pharmaceutical products and above all it can contribute to the reduction of environmental pollution.
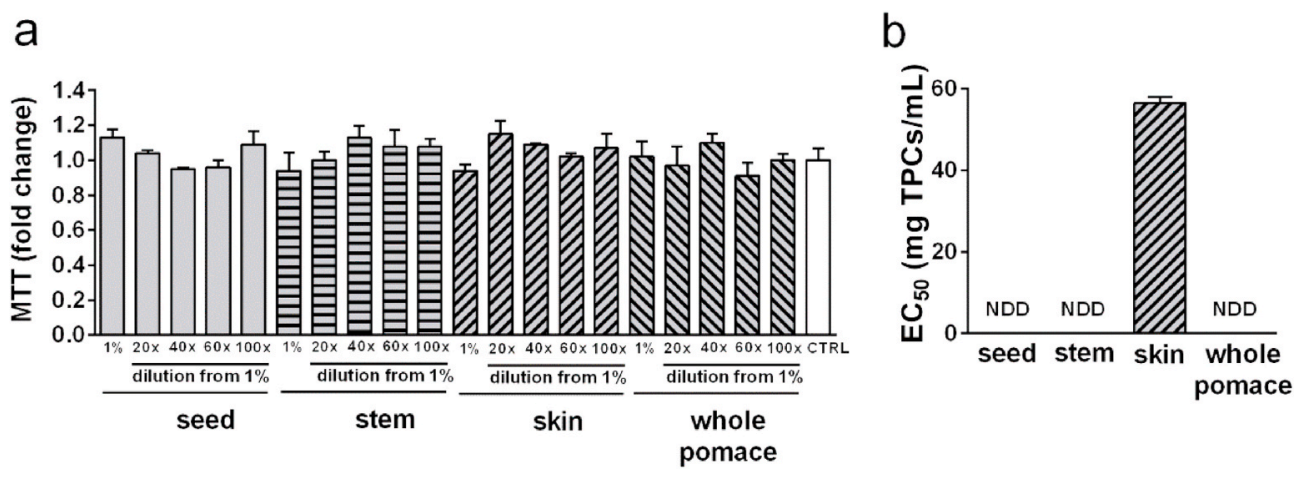

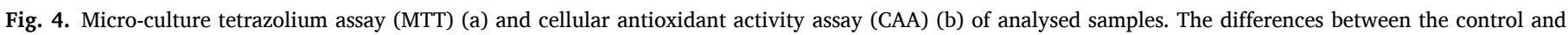

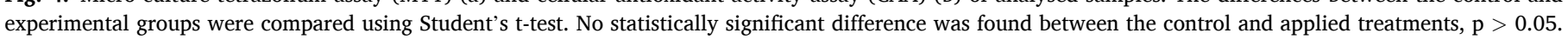




\section{CRediT authorship contribution statement}

Danijel D. Milinčić: Conceptualization, Methodology, Writing original draft, preparation, Investigation, Formal analysis, Validation. Nemanja S. Stanisavljević: Conceptualization, Methodology, Writing original draft, preparation, Investigation, Formal analysis, Validation. Aleksandar Ž. Kostić: Investigation. Svetlana Soković Bajić: Investigation. Milan O. Kojić: Supervision, Writing - review \& editing. Uroš M. Gašić: Investigation, Formal analysis, Validation. Miroljub B. Barać: Supervision, Writing - review \& editing. Sladjana P. Stanojević: Investigation. Živoslav $\mathbf{L j}$ Tešić: Conceptualization, Methodology, Writing - original draft, preparation, Supervision, Writing - review \& editing. Mirjana B. Pešić: Conceptualization, Methodology, Writing original draft, preparation, Investigation, Supervision, Writing - review \& editing.

\section{Declaration of competing interest}

The authors declare that they have no known competing financial interests or personal relationships that could have appeared to influence the work reported in this paper.

\section{Acknowledgments}

This publication was supported by the Ministry of Education, Science and Technological Development of the Republic of Serbia (Grants no. 451-03-68/2020-14/200116, 451-03-68/2020-14/200007 and 451-0368/2020-14/200042).

\section{Appendix A. Supplementary data}

Supplementary data to this article can be found online at https://doi. org/10.1016/j.lwt.2020.110739.

\section{References}

Amico, V., Napoli, E. M., Renda, A., Ruberto, G., Spatafora, C., \& Tringali, C. (2004) Constituents of grape pomace from the Sicilian cultivar 'Nerello Mascalese. Food Chemistry, 88(4), 599-607. https://doi.org/10.1016/j.foodchem.2004.02.022 Anastasiadi, M., Pratsinis, H., Kletsas, D., Skaltsounis, A.-L., \& Haroutounian, S. A. (2012). Grape stem extracts: Polyphenolic content and assessment of their in vitro antioxidant properties. Lebensmittel-Wissenschaft und -Technologie- Food Science and Technology, 48(2), 316-322. https://doi.org/10.1016/j.lwt.2012.04.006

Antoniolli, A., Fontana, A. R., Piccoli, P., \& Bottini, R. (2015). Characterization of polyphenols and evaluation of antioxidant capacity in grape pomace of the cv. Malbec. Food Chemistry, 178, 172-178. https://doi.org/10.1016/j. foodchem.2015.01.082

Cheng, Z., Moore, J., \& Yu, L. (2006). High-throughput relative DPPH radical scavenging capacity assay. Journal of Agricultural and Food Chemistry, 54(20), 7429-7436. https://doi.org/10.1021/jf0611668

Deng, Q., Penner, M. H., \& Zhao, Y. (2011). Chemical composition of dietary fiber and polyphenols of five different varieties of wine grape pomace skins. Food Research International, 44(9), 2712-2720. https://doi.org/10.1016/j.foodres.2011.05.026

Drosou, C., Kyriakopoulou, K., Bimpilas, A., Tsimogiannis, D., \& Krokida, M. (2015). A comparative study on different extraction techniques to recover red grape pomace polyphenols from vinification byproducts. Industrial Crops and Products, 75, 141-149. https://doi.org/10.1016/j.indcrop.2015.05.063

Ferreyra, S., Bottini, R., \& Fontana, A. (2019). Assessment of grapevine stems as source of phenolics with antioxidant properties. Revista de la Facultad de Ciencias Agrarias UNCuyo, 51(2). http://revistas.uncu.edu.ar/ojs3/index.php/RFCA/article/view/ 2728.

Ferreyra, S., Bottini, R., \& Fontana, A. (2021). Tandem absorbance and fluorescence detection following liquid chromatography for the profiling of multiclass phenolic compounds in different winemaking products. Food Chemistry, 338, 128030. https:// doi.org/10.1016/j.foodchem.2020.128030

Fontana, A. R., Antoniolli, A., \& Bottini, R. (2013). Grape pomace as a sustainable source of bioactive compounds: Extraction, characterization, and biotechnological applications of phenolics. Journal of Agricultural and Food Chemistry, 61(38), 8987-9003. https://doi.org/10.1021/jf402586f

González-Paramás, A. M., Esteban-Ruano, S., Santos-Buelga, C., de Pascual-Teresa, S., \& Rivas-Gonzalo, J. C. (2004). Flavanol content and antioxidant activity in winery byproducts. Journal of Agricultural and Food Chemistry, 52(2), 234-238. https://doi. org/10.1021/jf0348727

Gülçin, İ. (2012). Antioxidant activity of food constituents: An overview. Archives of Toxicology, 86(3), 345-391. https://doi.org/10.1007/s00204-011-0774-2
Halliwell, B. (2008). Are polyphenols antioxidants or pro-oxidants? What do we learn from cell culture and in vivo studies? Archives of Biochemistry and Biophysics, 476(2), 107-112. https://doi.org/10.1016/j.abb.2008.01.028

Hu, T. X., Chen, J. W., Xu, J. Y., \& Lu, J. Y. (1992). The role of YunZhi polysaccharopeptide and Ganoderma lucidum polysaccharide in scavenging ROS Acta Biochimica et Biophysica Sinica, 24(5), 465-470.

Kammerer, D., Claus, A., Carle, R., \& Schieber, A. (2004). Polyphenol screening of pomace from red and white grape varieties (Vitis vinifera L.) by HPLC-DAD-MS/MS. Journal of Agricultural and Food Chemistry, 52(14), 4360-4367. https://doi.org/ 10.1021/jf049613b

Kellett, M. E., Greenspan, P., \& Pegg, R. B. (2018). Modification of the cellular antioxidant activity (CAA) assay to study phenolic antioxidants in a Caco-2 cell line. Food Chemistry, 244, 359-363. https://doi.org/10.1016/j.foodchem.2017.10.035

Ky, I., Lorrain, B., Kolbas, N., Crozier, A., \& Teissedre, P.-L. (2014). Wine by-products: Phenolic characterization and antioxidant activity evaluation of grapes and grape pomaces from six different French grape varieties. Molecules, 19(1), 482-506. https://doi.org/10.3390/molecules19010482

Liu, X., Li, J., Tian, Y., Liao, M., \& Zhang, Z. (2016). Influence of berry heterogeneity on phenolics and antioxidant activity of grapes and wines: A primary study of the new winegrape cultivar Meili (Vitis vinifera L.). PloS One, 11(3), Article e0151276. https://doi.org/10.1371/journal.pone.0151276

Milinčić, D. D., Kostić, A.Ž., Špirović Trifunović, B. D., Tešić, Ž. L., Tosti, T. B., Dramićanin, A. M., et al. (2020). Grape seed flour of different grape pomaces: Fatty acid profile, soluble sugar profile and nutritional value. [Vitis vinifera, marc, soluble carbohydrates, long-chain organic acids, index of atherogenicity. Index of Thrombogenicity], 85(3), 15. https://doi.org/10.2298/jsc190713117m. 2020.

Mitić, M. N., Souquet, J. M., Obradović, M. V., \& Mitić, S. S. (2012). Phytochemical profiles and antioxidant activities of Serbian table and wine grapes. [Article]. Food Science and Biotechnology, 21(6), 1619-1626. https://doi.org/10.1007/s10068-0120215-X

Mosmann, T. (1983). Rapid colorimetric assay for cellular growth and survival: Application to proliferation and cytotoxicity assays. Journal of Immunological Methods, 65(1), 55-63. https://doi.org/10.1016/0022-1759(83)90303-4

Muhlack, R. A., Potumarthi, R., \& Jeffery, D. W. (2018). Sustainable wineries through waste valorisation: A review of grape marc utilisation for value-added products. Waste Management, 72, 99-118. https://doi.org/10.1016/j.wasman.2017.11.011

Oliveira, J., Alhinho da Silva, M., Teixeira, N., De Freitas, V., \& Salas, E. (2015). Screening of anthocyanins and anthocyanin-derived pigments in red wine grape pomace using LC-DAD/MS and MALDI-TOF techniques. Journal of Agricultural and Food Chemistry, 63(35), 7636-7644. https://doi.org/10.1021/acs.jafc.5b00256

Pantelić, M. M., Dabić Zagorac, D.Č., Davidović, S. M., Todić, S. R., Bešlić, Z. S., Gašić, U. M., et al. (2016). Identification and quantification of phenolic compounds in berry skin, pulp, and seeds in 13 grapevine varieties grown in Serbia. Food Chemistry, 211(Supplement C), 243-252. https://doi.org/10.1016/j. foodchem.2016.05.051

Peixoto, C. M., Dias, M. I., Alves, M. J., Calhelha, R. C., Barros, L., Pinho, S. P., et al. (2018). Grape pomace as a source of phenolic compounds and diverse bioactive properties. Food Chemistry, 253, 132-138. https://doi.org/10.1016/j. foodchem.2018.01.163

Pešić, M. B., Milinčić, D. D., Kostić, A.Ž., Stanisavljević, N. S., Vukotić, G. N., Kojić, M. O., et al. (2019). In vitro digestion of meat- and cereal-based food matrix enriched with grape extracts: How are polyphenol composition, bioaccessibility and antioxidant activity affected? Food Chemistry, 284, 28-44. https://doi.org/10.1016/j. foodchem.2019.01.107

Pintać, D., Majkić, T., Torović, L., Orčić, D., Beara, I., Simin, N., et al. (2018). Solvent selection for efficient extraction of bioactive compounds from grape pomace. Industrial Crops and Products, 111, 379-390. https://doi.org/10.1016/j. indcrop. 2017.10.038

Ribeiro, L. F., Ribani, R. H., Francisco, T. M. G., Soares, A. A., Pontarolo, R., \& Haminiuk, C. W. I. (2015). Profile of bioactive compounds from grape pomace (Vitis vinifera and Vitis labrusca) by spectrophotometric, chromatographic and spectral analyses. Journal of Chromatography B, 1007(Supplement C), 72-80. https://doi.org/ 10.1016/j.jchromb.2015.11.005

Rockenbach, I. I., Jungfer, E., Ritter, C., Santiago-Schübel, B., Thiele, B., Fett, R., et al. (2012). Characterization of flavan-3-ols in seeds of grape pomace by CE, HPLC-DAD$\mathrm{MS}^{\mathrm{n}}$ and LC-ESI-FTICR-MS. Food Research International, 48(2), 848-855. https://doi. org/10.1016/j.foodres.2012.07.001

Sánchez, B., Fernández-García, M., Margolles, A., de los Reyes-Gavilán, C. G., \& RuasMadiedo, P. (2010). Technological and probiotic selection criteria of a bile-adapted Bifidobacterium animalis subsp. lactis strain. International Dairy Journal, 20(11), 800-805. https://doi.org/10.1016/j.idairyj.2010.06.004

Tseng, A., \& Zhao, Y. (2012). Effect of different drying methods and storage time on the retention of bioactive compounds and antibacterial activity of wine grape pomace (Pinot noir and Merlot). Journal of Food Science, 77(9), H192-H201. https://doi.org/ 10.1111/j.1750-3841.2012.02840.x

Wang, H. R., Sui, H. C., Ding, Y. Y., \& Zhu, B. T. (2018). Stimulation of the production of prostaglandin E2 by ethyl gallate, a natural phenolic compound richly contained in Longan. [Article]. Biomolecules, 8(3). https://doi.org/10.3390/biom8030091

Wolfe, K. L., \& Liu, R. H. (2007). Cellular antioxidant activity (CAA) assay for assessing antioxidants, foods, and dietary supplements. Journal of Agricultural and Food Chemistry, 55(22), 8896-8907. https://doi.org/10.1021/jf0715166

Yu, J., \& Ahmedna, M. (2013). Functional components of grape pomace: Their composition, biological properties and potential applications. International Journal of 
Food Science and Technology, 48(2), 221-237. https://doi.org/10.1111/j.1365 2621.2012.03197.x

Zdunić, G., Gođevac, D., Šavikin, K., Krivokuća, D., Mihailović, M., Pržić, Z., et al. (2019). Grape seed polyphenols and fatty acids of autochthonous prokupac vine variety from Serbia. [Article]. Chemistry and Biodiversity, 16(7). https://doi.org/ 10.1002/cbdv.201900053
Zhang, X.-K., Li, S.-Y., Zhao, X., Pan, Q.-H., Shi, Y., \& Duan, C.-Q. (2020). HPLC-MS/MSbased targeted metabolomic method for profiling of malvidin derivatives in dry red wines. Food Research International (Ottawa, Ont.), 134, 109226. https://doi.org/ 10.1016/j.foodres.2020.109226 